\title{
Calcium export from neurons and multi-kinase signaling cascades contribute to ouabain neuroprotection in hyperhomocysteinemia
}

\section{Maria A. Ivanova}

Sechenov Institute of Evolutionary Physiology and Biochemistry of the Russian Academy of Sciences

Arina D. Kokorina

Sechenov Institute of Evolutionary Physiology and Biochemistry of the Russian Academy of Sciences

\section{Polina D. Timofeeva}

Sechenov Institute of Evolutionary Physiology and Biochemistry of the Russian Academy of Sciences

\section{Tatiana V. Karelina}

Sechenov Institute of Evolutionaty Physiology and Biochemistry of the Russian Academy of Sciences

\section{Polina A. Abushik}

Sechenov Institute of Evolutionaty Physiology and Biochemistry of the Russian Academy of Sciences

\section{Julia D. Stepanenko}

Sechnov Institute of Evolutionary Physiology and Biochemistry of the Russian Academy of Sciences

\section{Dmitry A. Sibarov}

Sechenov Institute of Evolutionary Physiology and Biochemistry of the Russian Academy of Sciences

\section{Sergei M Antonov ( $\square$ antonov452002@yahoo.com)}

Sechenov Institute of Evolutionary Physiology and Biochenistry of the Russian Academy od Sciences https://orcid.org/0000-0002-0644-9330

\section{Research article}

Keywords: Homocysteine, glutamate, NMDA receptors, cortical neurons, ouabain, Na,K-ATPase, PKC, PKA, calcium

Posted Date: June 3rd, 2020

DOI: https://doi.org/10.21203/rs.3.rs-32426/v1

License: (c) (1) This work is licensed under a Creative Commons Attribution 4.0 International License. Read Full License 


\section{Abstract}

Background: Subnanomolar ouabain binding to the Na,K-ATPase triggers intracellular signaling, prevents an overload of neurons with $\mathrm{Ca}^{2+}$, and their apoptosis caused by glutamate receptor agonists. Elevated plasma homocysteine ( $\mathrm{HCY}$ ), known as hyperhomocysteinemia, represents a risk factor for stroke and can exacerbate many neuronal disorders. $\mathrm{HCY}$ acts as a persistent $N$-methyl-D-aspartate receptor (NMDAR) agonist, which, in contrast to glutamate, desensitizes NMDARs containing GluN2B subunits. Mechanisms of HCY neurotoxicity remain not clearly understood since GluN2B-containing NMDARs provide a major contribution to excitotoxicity among glutamate receptors.

Methods: Using fluorescent tools combined with the confocal microscopy, we compared 0.1 - $1 \mathrm{nM}$ ouabain effects on the intracellular $\mathrm{Ca}^{2+}$ signaling, on the mitochondrial inner membrane voltage and the cell viability in primary cultures of rat cortical neurons in glutamate and HCY neurotoxic insults. We also studied an apoptosis-related protein expression and the involvement of some kinases in ouabain mediated effects.

Results: In short insults HCY was less potent than glutamate as a neurotoxic agent. This amino acid induced the voltage loss $\left(\Delta \varphi_{\text {mit }}\right)$ of 0.2 of the total mitochondrial inner membrane voltage $\left(\varphi_{\text {mit }}\right)$ instead of $\Delta \varphi_{\text {mit }}=0.7$ for glutamate. We have found that subnanomolar ouabain exhibited rapid and postponed neuroprotective effects on neurons and (1) rapidly reduced the $\mathrm{Ca}^{2+}$ overload of neurons and the voltage loss of inner mitochondrial membranes evoked by glutamate and $\mathrm{HCY}$, and (2) prevented neuronal apoptosis during $24 \mathrm{~h}$ treatments with glutamate or HCY. Using a set of specific kinase inhibitors such as PKA inhibitor, chelerythrine, and KN93, we demonstrated the role of multi-kinase signaling pathways involving PKC and PKA in neuronal survival caused by ouabain in hyperhomocysteinemia.

Conclusions: Subnanomolar ouabain prevents neurodegeneration caused by glutamate and HCY. For both amino acids, ouabain evokes an acceleration of $\mathrm{Ca}^{2+}$ export by sodium-calcium exchangers from neurons preventing the voltage loss by mitochondrial inner membranes that rescue neurons in short insults. In prolonged insults, ouabain triggers intracellular neuroprotective cascades, including activation of PKA and PKC for HCY, but not for glutamate. This suggests that different appropriate pharmacology for hyperhomocysteinemia and glutamate excitotoxicity could be applied for clinical treatments.

\section{Background}

Homocysteine (2-amino-4-sulfanylbutanoic acid, HCY), a thiol-containing amino acid, represents an intermediate product for methionine and cysteine synthesis, which proper metabolism critically depends upon supplies of folic acid and vitamin $\mathrm{B}_{12}$. Under physiological conditions, $\mathrm{HCY}$ is present in the human plasma in concentrations of 7-14 $\mu \mathrm{M}$ [1]. Both mutations in enzymes of methionine and cysteine synthesis and dietary deficiencies of folic acid and vitamin $\mathrm{B}_{12}$ cause an accumulation of HCY in the blood and cerebrospinal fluid. Elevated plasma HCY levels, known as hyperhomocysteinemia, represent a risk factor for stroke [2] and can exacerbate many neuronal disorders, including Parkinson's [3, 4] and 
Alzheimer's diseases [5]. In severe hyperhomocysteinemia, the plasma HCY composition can exceed 100 $\mu \mathrm{M}[6]$. It is well established that large HCY concentrations perform neurotoxicity [7,8], causing apoptosis of neurons of different brain regions [9]. The ability of HCY to activate ionotropic glutamate receptors, particularly of $\mathrm{N}$-methyl-D-aspartate - type (NMDARs) and metabotropic glutamate receptors of type - 5 (mGluR5s) is generally thought to underlay the neurotoxicity $[7,10]$. When studied at concentrations up to $1 \mathrm{mM}, \mathrm{HCY}$ activated NMDAR currents, which amplitudes increased with the HCY concentration ([HCY]) increase [7,11]. The effect depended on GluN2 subunit compositions of NMDARs [11]. When studied at physiologically relevant concentrations, its appeared that all diheteromeric NMDARs (containing GluN2A, $\mathrm{B}, \mathrm{C}$ or D) are well activated by $\mathrm{HCY}$ with $\mathrm{IC}_{50}$ varied from about $10 \mu \mathrm{M}$ (for GluN2A) to $80 \mu \mathrm{M}$ (for GluN2C) $[12,13]$. Whereas NMDARs containing GluN2A/C or D subunits did not reveal desensitization during the HCY activation [12,13], currents through GluN1/GluN2B NMDARs briefly declined to about $15 \%$ of the peak amplitude because of the desensitization [12]. This observation exhibits why NMDARs containing GluN2A subunits, but not the GluN2B ones, mostly contribute to HCY-induced excitotoxicity in cortical neurons [12-16]. Cerebellar neurons expressing NMDARs containing GluN2C or 2D are also sensitive to the excitotoxic action of $\mathrm{HCY}$ since these receptors do not reveal desensitization during the HCY activation [13].

To compare neurotoxicity caused by glutamate and $\mathrm{HCY}$, which are both endogenous amino acids, a much broader range of molecular targets for glutamate, than for $\mathrm{HCY}$, in the brain including all ionotropic and metabotropic glutamate receptors as well as glutamate transporters should be taken into account. The $\mathrm{Ca}^{2+}$ influx through $\mathrm{Ca}^{2+}$-permeable AMPA receptors and synaptic GluN2A- and extrasynaptic GluN2B-containing NMDARs with subsequent ERK MAPK and Caspase-3 activation play a role in the glutamate-induced neurotoxicity [17-19]. In contrast, $\mathrm{HCY}$ activates synaptic GluN2A-containing NMDARs and desensitized extrasynaptic NMDARs, causing excitatory transmission hyperactivity $[20,21]$. Therefore, the HCY-induced neurotoxicity differs from the glutamate one in many aspects, most likely, including intracellular signaling cascades as well.

Previously we have shown that $\mathrm{Ca}^{2+}$ overload of neurons caused by glutamate, NMDA and kainate can be prevented by subnanomolar concentrations of ouabain acting via sodium-potassium ATPase (NKA) $[22,23]$ and by activation of cAMP-dependent signaling [24] that significantly improves neuronal viability. NKA is a critical element of cell ionic balance providing $\mathrm{Na}^{+}$and $\mathrm{K}^{+}$trans-membrane gradients for other electrolyte and organic transporters and ion channels. The value of these processes for cell functioning is highlighted by the observation that the NKA enzymatic activity inhibition results in cell death. There is a growing pool of evidence that NKA also acts as a signal transducer [25-29]. Ouabain is a well studied cardiotonic steroid, which can specifically bind to NKA and inhibit its pump activity. Neurons express a1and a3-isoforms of NKA. NKAa1 is many-folds less sensitive to ouabain than NKAa3, which is inhibited by ouabain at concentrations above $10 \mathrm{nM}$ [30-31]. Ouabain at $1 \mathrm{nM}$, however, potentiates ion transport by NKAa3 without any effect on NKAa1 [30]. Thus sub-saturating concentrations of ouabain (usually 1 $\mathrm{nM}$ and below) do not inhibit NKA, but activate various metabotropic signaling cascades via Src-kinase [32], IP ${ }_{3}$-receptor [33], $\mathrm{Na}$ /Ca-exchanger [22,34], protein kinases phosphatidylinositide 3-kinase and Akt 
[35]. At these concentrations, ouabain can regulate $\mathrm{Ca}^{2+}$ extrusion from neurons by $\mathrm{Na}^{+} / \mathrm{Ca}^{2+}$-exchangers interacting with NKA in the lipid rafts, which may also influence the functioning of NMDARs $[36,37]$.

Although NKA signaling triggered by low concentrations of cardiotonic steroids results in neuroprotection $[22,38]$, the mechanisms and the particular intracellular cascades involved in these effects are not fully understood.

In excitotoxic stress, NKA-signaling has both immediate effects on $\mathrm{Ca}^{2+}$ transport $[22,23]$ and postponed effects on apoptotic pathways and neuronal viability $[22,38]$. Recently it has been demonstrated that calcitonin gene-related peptide (CGRP), which is a mediator of pain in migraine [39], causes

neuroprotection of different neurons against HCY by activation of multi-kinase signaling [40]. Here in the model of short $(4 \mathrm{~h})$ and long $(24 \mathrm{~h})$ insults of glutamate and HCY on cortical neurons in primary culture, we analyze neuronal viability and involvement of kinases in ouabain induced neuroprotection. We also compare the ouabain effects on glutamate and $\mathrm{HCY}$ elicited intracellular $\mathrm{Ca}^{2+}$ responses and changes of mitochondrial inner membrane potential.

\section{Materials And Methods}

The effects of ouabain on neuronal survival have been studied in models of short-term $4 \mathrm{~h}$ and long-term $24 \mathrm{~h}$ action of $\mathrm{HCY}$ or glutamate. An excess of glutamate was taken as a well-known reference model of neurodegeneration caused by over-excitation of neurons. An excess of $\mathrm{HCY}$ in an extracellular solution was utilized to reproduce hyperhomocysteinemia.

\section{Material and animals}

Chemicals were from Sigma, unless otherwise indicated. All procedures using animals were in accordance with recommendations of the Federation for Laboratory Animal Science Associations and approved by the local Institutional Animal Care and Use Committees.

\section{Primary cortical culture}

The procedure of culture preparation from rat embryos was previously described [41, 42]. Wistar rats (provided by the Sechenov Institute's Animal Facility) 16-17 days pregnant (overall 27 animals in this study) were sacrificed by $\mathrm{CO}_{2}$ inhalation. Fetuses were removed and their cerebral cortices were isolated, enzymatically dissociated, and used to prepare primary neuronal cultures. Cells were used for experiments after 10-14 days in culture (10-14 DIV) [41, 42]. Cells were grown in Neurobasal ${ }^{\mathrm{Tm}}$ culture medium supplemented with B-27 (Gibco) on glass coverslips coated with poly-D-lysine.

\section{Quantitation of cell viability}

To test the viability, cultured cells were incubated for 4 or $24 \mathrm{~h}$ in normal medium (control conditions) or in medium containing $100 \mu \mathrm{M} \mathrm{L-glutamate} \mathrm{(Glu)} \mathrm{or} 100 \mu \mathrm{M} \mathrm{L-homocysteine} \mathrm{(HCY).} \mathrm{Agonists} \mathrm{were} \mathrm{also}$ combined with 0.1 or $1 \mathrm{nM}$ ouabain. In these experiments both glutamate receptor agonists were coapplied with $30 \mu \mathrm{M}$ glycine, to ensure activation of NMDA receptors. The specific proteinkinase A (PKA) 
inhibitor fragment 14-22 (PKAi), myristoylated trifluoroacetate, was used to inhibit PKA and subsequent cAMP signaling pathways; chelerythrine was applied to inhibit proteinkinase $C$ (PKC) and KN93 - to inhibit $\mathrm{Ca}^{2+} /$ calmodulin-dependent protein kinase type II (CaMKII).

Cell viability was measured by fluorescent viability assay (FVA) described earlier [41]. Cells were stained with $0.001 \%$ acridine orange for $30 \mathrm{~s}$ in the basic solution $(152 \mathrm{mM} \mathrm{NaCl}, 2.5 \mathrm{mM} \mathrm{KCl}, 10 \mathrm{mM}$ glucose, $2 \mathrm{mM} \mathrm{CaCl}_{2}, 1 \mathrm{mM} \mathrm{MgCl}_{2}, 10 \mathrm{mM} \mathrm{HEPES}$, pH adjusted to 7.4 using $\mathrm{NaOH}$ ). After complete washout of contaminating acridine orange, cells were exposed to $0.004 \%$ ethidium bromide for $30 \mathrm{~s}$ in the basic solution followed by the dye washout. This staining was performed immediately before each measurement. Fluorescence images were captured using Leica TCS SP5 MP scanning confocal microscope (Leica Microsystems Inc.). For two-channel imaging the fluorescence was excited with $488 \mathrm{~nm}$ laser and the emitted fluorescence was acquired at 500 to $560 \mathrm{~nm}$ (green region of spectrum for acridine orange) and above $600 \mathrm{~nm}$ (red region of spectrum for ethidium bromide). Single focal plane images from both channels were merged and analyzed with standard Leica LAS AF Software (Leica MicrosystemsInc.) and ImageJ software using custom written plug-in [22]. On the resulting image, noncolocalized green and red pixels were attributed to live and necrotic neurons, respectively. Yellow-orange pixels with colocalized green and red fluorescence were attributed to the nuclei of apoptotic neurons.

\section{Western Blot analysis}

The cells were washed twice with cold PBS and leased in a buffer containing $50 \mathrm{mM} \mathrm{Tris-HCl}, 150 \mathrm{mM}$ $\mathrm{NaCl}, 1 \mathrm{mM}$ EDTA, $1 \mathrm{mM}$ EGTA, $10 \%$ glycerin, 1\% Triton X-100, $1 \mathrm{mM} \mathrm{Na}_{3} \mathrm{VO}_{4}, 1 \mathrm{mM} \mathrm{NaF}, 0.5 \mathrm{mM}$ PMSF and a cocktail of protease inhibitors ( $1: 500$, Sigma, USA) for $10 \mathrm{~min}$ on ice. After lysis, the cells were scraped off the glasses and centrifuged for $15 \mathrm{~min}$ at $15000 \mathrm{~g} .1 / 4$ part of the buffer for electrophoretic samples (40 mM Tris, pH 6.8, 10\% SDS, 20\% 2-mercaptoethanol and 40\% glycerol) was added to the supernatant and incubated for $5 \mathrm{~min}$ at $100^{\circ} \mathrm{C}$. Proteins were loaded on $10 \%$ polyacrylamide gel for electrophoresis and then transferred onto polyvinylidene fluoride membranes in a cold room during the night at $20 \mathrm{~V}$ in a small BioRad chamber. The quality of the transfer was checked by marking the gel with Coomasie dye. Non-specific binding sites were blocked with Tris-buffered saline-Tween (0.02 M Tris, $0.137 \mathrm{M} \mathrm{NaCl}$ and $0.1 \%$ Tween 20 ) containing $5 \%$ non-fat dried milk and probed overnight for protein of interest with the following primary antibodies: polyclonal rabbit antibodies to protein Caspase-3 (dilution 1:1500, Sigma C-8487), monoclonal rabbit antibodies to AIF (dilution 1:1000, abcam ab32516), monoclonal mouse antibodies to BAX (dilution 1:2000, abcam ab5714), polyclonal rabbit antibodies to Bcl-2 (dilution 1:200, abcam ab7973), monoclonal mouse antibodies to p53 (dilution 1:150, Sigma P5813). $\beta$-Actin protein (monoclonal mouse antibodies, dilution 1:1000, Sigma A3854) served as the control for gel loading. The excess of primary antibodies was washed out and a solution of corresponding horseradish peroxidase-conjugated secondary antibodies was applied for $2 \mathrm{~h}$ : antirabbit to Cas-3, AIF, Bcl-2 proteins (1:2000, Dako P0448 dilution) and anti-mouse to BAX, p53 proteins (1:2000, Dako P0447 dilution). Bands were detected by chemiluminescence, visualized on X-ray film, and quantified by densitometry in ImageJ software.

\section{Calcium imaging}


Cortical neurons in primary culture 10-14 days in vitro (DIV) were rinsed with the basic solution followed by loading with $2 \mu \mathrm{M}$ Fluo-8 acetoxymethyl ester (Fluo-8 AM) at room temperature for $60 \mathrm{~min}$ (in the basic solution) followed by 20 min incubation in pure basic solution, after which dishes were transferred to a Leica TCS SP5 MP inverted microscope (Leica Microsystems, GmbH, Wetzlar, Germany) and permanently perfused with the basic solution at a flow rate of $1.2 \mathrm{ml} / \mathrm{min}$. The setup was equipped by the fast perfusion system, which allowed rapid application of various compounds. $\mathrm{HCY}(100 \mu \mathrm{M})$ or glutamate $(100 \mu \mathrm{M})$ were added together with $30 \mu \mathrm{M}$ glycine. Fluorescence was excited with $488 \mathrm{~nm}$ laser and detected at 510-560 nm range with 2 s sampling interval (frame 512 ×512 px).

\section{Mitochondrial membrane potential imaging}

Cortical neurons were loaded with $5 \mu \mathrm{M}$ Rhodamine 123 for $30 \mathrm{~min}$ in the basic solution. The emitted fluorescence was detected via Leica TCS SP5 MP inverted microscope (Leica Microsystems, Inc.). The wavelengths $488 \mathrm{~nm}$ and $510-530 \mathrm{~nm}$ were used for excitation and emission, respectively for detection of mitochondrial inner membrane potential $\left(\varphi_{\text {mit }}\right)$. Sampling interval was set to $\sim 1 \mathrm{~s}$ (frame $512 \times 512$ px). In experiments $\mathrm{HCY}(100 \mu \mathrm{M})$ or glutamate $(100 \mu \mathrm{M})$ always were applied with $30 \mu \mathrm{M}$ glycine. To test the functional state of mitochondria, the oxidative phosphorylation inhibitor, $4 \mu \mathrm{M} \mathrm{CCCP} \mathrm{(m-chlorophenyl}$ hydrazone, Sigma) was applied at the end of experiment [43].

\section{Analysis and statistics}

For all experiments, $n$ represents the number of experiments. Each of experiments was performed on a single coverslip with cultured neurons. To analyze average and all comparisons were generated using ANOVA with Tukey's post-hoc test. The results are expressed as mean of data \pm SEM unless otherwise stated. The level of statistical significance was set to $p<0.05$. Data marked by $*$, **, or $* \star \star$ are significantly different with $p<0.05, p<0.01, p<0.001$ correspondently.

\section{Results}

\section{Ouabain enhances the viability of neurons in short excitotoxic stress}

The neuroprotective effect of ouabain was assessed in the model of excitotoxic stress elicited by $4 \mathrm{~h}$ incubation of neurons in the bathing solution containing $100 \mu \mathrm{M}$ glutamate or $100 \mu \mathrm{M} \mathrm{HCY}$ (Fig. 1). The fraction of live cells (Fig. 1a) was significantly decreased $(p=0.0001, n=8)$ due to apoptosis $(p=$ $0.0001, n=8)$ and necrosis ( $p=0.002, n=8)$ after $4 \mathrm{~h}$ incubation in the $100 \mu \mathrm{M}$ glutamate-containing bathing solution (Fig. 1b). The neuronal viability was found to be unchanged from control values if glutamate was co-applied with 0.1 or $1 \mathrm{nM}$ ouabain (Fig. 1c and d). A similar neurotoxic effect was elicited by $4 \mathrm{~h}$ incubation in the bathing solution with $100 \mu \mathrm{M} \mathrm{HCY}$, while the addition of 0.1 or $1 \mathrm{nM}$ ouabain prevented necrosis and apoptosis of neurons (Fig. 1e). From these experiments, we may conclude that $4 \mathrm{~h}$ treatments with equimolar concentrations of either glutamate or $\mathrm{HCY}$ resulted in apoptosis and necrosis (Table 1). Subnanomolar concentrations of ouabain, however, prevented the 
neurotoxic effects of these compounds. Because apoptosis was more pronounced than necrosis in the effects of both amino acids, we further analyzed the influence of ouabain on the expression of pro- and anti-apoptotic proteins as well as on calcium and energy balance in neurons.

\section{Ouabain prevents pro-apoptotic proteins expression in short excitotoxic insults}

As far as ouabain inhibited neuronal apoptosis, we studied whether the expression of proteins involved in apoptosis pathways and anti-apoptotic proteins are affected by ouabain during $4 \mathrm{~h}$ neurotoxic action of glutamate. We studied expression of proteins such as Caspase-3 (Cas-3), p53, and BAX, which are involved in the caspase-dependent apoptotic pathway. The expression of apoptosis-inducing factor (AIF) was also evaluated together with $\mathrm{Bcl}-2$, which antagonizes AIF release from mitochondria.

Western blotting confirmed that AIF, Cas-3, p53, and BAX expression were elevated, and Bcl-2 expression was suppressed after $4 \mathrm{~h}$ incubation in the bathing solution containing $100 \mu \mathrm{M}$ glutamate (Fig. 2). The glutamate-containing bathing solution combined with $1 \mathrm{nM}$ ouabain prevented an increase of proapoptotic protein expression, and the Bcl-2 expression remained at the control level. From these experiments, it became clear that ouabain at $1 \mathrm{nM}$ can antagonize the development of apoptotic signaling pathways so that the pattern of protein expression in the presence of glutamate and ouabain was found to be similar to the control conditions (Fig. 2).

\section{Ouabain suppresses intracellular $\mathrm{Ca}^{2+}$ overload and mitochondrial dysfunction of neurons}

It generally accepted that the Bcl-2 level is positively correlated with normal mitochondria functioning and energy metabolism. A decrease in Bcl-2 levels is widely used as a marker of apoptosis [44]. Considering that ouabain restores $\mathrm{Bcl}-2$ expression in excitotoxic insults, in further experiments, we used fluorescent imaging to monitor free intracellular $\mathrm{Ca}^{2+}$ concentration $\left(\left[\mathrm{Ca}^{2+}\right]\right.$ ) and changes of the internal membrane potential of mitochondria in neurons during applications of glutamate or $\mathrm{HCY}$ in the absence or in the presence of $1 \mathrm{nM}$ ouabain.

The intracellular $\mathrm{Ca}^{2+}$ responses elicited by $100 \mu \mathrm{M}$ glutamate application (Fig. 3a, b) demonstrated the permanent $\mathrm{Ca}^{2+}$ elevation as long as glutamate was present. Some neurons generated $\mathrm{Ca}^{2+}$ transients in response to glutamate (Fig. 3c), which contributed to intracellular $\left[\mathrm{Ca}^{2+}\right]$ elevation. Any way an application of $1 \mathrm{nM}$ ouabain reduced glutamate-evoked raise of intracellular $\left[\mathrm{Ca}^{2+}\right.$ (Fig. $\left.3 \mathrm{~b}\right)$ and suppressed $\mathrm{Ca}^{2+}$ transients (Fig. 3c) that prevented cytosolic $\mathrm{Ca}^{2+}$ accumulation (Fig. 3d). Therefore in the presence of ouabain, the averaged glutamate elicited $\left[\mathrm{Ca}^{2+}\right]$ elevation did not exceed control values ( $n$ $=5$, Fig. $3 \mathrm{~b}$ and $\mathrm{c}$ ) being strongly reduced as compared to those obtained in the absence of ouabain (Fig. 3d, $\mathrm{p}=0.0006, n=5$ ). 
The $\mathrm{Ca}^{2+}$ entry in neurons in response to glutamate exposure was accompanied by the significant loss of internal membrane voltage of mitochondria (Fig. 3e), which reflects the energy cost for excessive intracellular $\mathrm{Ca}^{2+}$ removal from the cytoplasm by intracellular $\mathrm{Ca}^{2+}$ stores including mitochondria and ion transport mechanisms. The voltage loss $\left(\Delta \varphi_{\text {mit }}\right)$ reached 0.7 of maximal level $\left(\varphi_{\text {mit }}\right)$ estimated by CCCP, which, as known, causes a mitochondrial respiratory chain disruption resulting in the ATP synthesis collapse and the energy depletion. In the presence of ouabain, glutamate did not evoke any significant loss of inner membrane voltage of mitochondria (Fig. 3f).

Therefore glutamate short insults cause the intracellular $\mathrm{Ca}^{2+}$ accumulation in neurons (Fig. $3 \mathrm{~d}$ ) that may reach over $500 \%$ of control ( $p=0.0006, n=7$, Fig. $3 g$ ) and mitochondrial dysfunction (Fig, $3 e$ ) which is characterized by $\Delta \varphi_{\text {mit }}=0.7$ (Fig. $3 \mathrm{~g}$ ). In the presence of $1 \mathrm{nM}$ ouabain, these glutamate effects were not observed (Fig. 3g).

Similar results were obtained in experiments with $100 \mu \mathrm{M} \mathrm{HCY,} \mathrm{which,} \mathrm{however,} \mathrm{differed} \mathrm{from} \mathrm{the}$ glutamate effects quantitatively. The permanent 3-fold elevation of intracellular $\left[\mathrm{Ca}^{2+}\right]$ evoked by $\mathrm{HCY}(\mathrm{p}$ $=0.0004, n=4$, Fig. 4a) was significantly suppressed by ouabain $(p=0.0002, n=4$, Fig. 4b), which abolished cytosolic $\mathrm{Ca}^{2+}$ accumulation (Fig. 4c). The $\Delta \varphi_{\text {mit }}$ value for $\mathrm{HCY}$ was found to be $0.2(\mathrm{p}=$ $0.0002, n=5$, Fig. 4 d), which is much smaller than those for Glu ( $p=0.0006, n=7$, Fig. $3 g)$ and was not observed in the presence of $1 \mathrm{nM}$ ouabain (Fig. 4e). Therefore $\mathrm{HCY}$ caused smaller $\mathrm{Ca}^{2+}$ responses and produced a less burdening effect on the cell energy balance than Glu (Fig. 4f). Ouabain effectively prevented both the $\mathrm{HCY}$ evoked $\mathrm{Ca}^{2+}$ accumulation and the drop of mitochondrial inner membrane potential.

Thus at $100 \mu \mathrm{M}$, both studied amino acids caused the intracellular [ $\left.\mathrm{Ca}^{2+}\right]$ elevation and accompanying loss of the mitochondrial inner membrane voltage. While the effects of HCY were less pronounced than for glutamate, ouabain was able to prevent the effects of both amino acids.

\section{Ouabain enhances the viability of neurons in long excitotoxic stress triggering multi-kinase signaling cascades}

Long-term $24 \mathrm{~h}$ incubation of neurons in the presence of $100 \mu \mathrm{M} \mathrm{HCY}$ (Fig. 5a) as well as of Glu resulted in an increase of neuronal apoptosis ( $n=8, \mathrm{p}=0.03$ for Glu and $n=8, \mathrm{p}=0.0008$ for HCY). Combined applications of $0.1 \mathrm{nM}-1 \mathrm{nM}$ ouabain with Glu or HCY, completely prevented apoptosis induced by both NMDAR agonists (Fig. 5b). Quantitative comparison of the data obtained for Glu and HCY and in the presence of $0.1 \mathrm{nM}$ or $1 \mathrm{nM}$ ouabain are shown in Fig. $5 \mathrm{c}$.

To evaluate the intracellular anti-apoptotic cascades triggered by ouabain, we further studied the involvement of protein kinases in these processes using their selective inhibitors. The effects of PKA inhibition by PKAi $(0.6 \mu \mathrm{M})$, PKC inhibition by Chel $(1 \mu \mathrm{M})$, or CaMKII inhibition by KN93 $(3 \mu \mathrm{M})$ were studied in short- and long-term protocols of the excitotoxic stress experiments. The short-term $4 \mathrm{~h}$ 
incubation of neurons with agonists $+1 \mathrm{nM}$ ouabain and combined with kinase inhibitors did not substantially change neuronal survival and apoptosis (Fig. 6a). From this observation, we may conclude that short-term anti-apoptotic effects of ouabain do not depend on studied kinases and probably involve some fast-acting "emergency" mechanisms. In $24 \mathrm{~h}$ treatment of neurons with agonists, some difference between Glu and HCY effects was found. For example, the inhibition of all kinases under study had no considerable effects on ouabain caused neuroprotection against glutamate neurotoxicity. In contrast, the inhibition of either PKA or PKC prevented anti-apoptotic effects of ouabain during $24 \mathrm{~h}$ treatment with $\mathrm{HCY}$ (Fig. 6b). KN93 did not prevent neuroprotection of ouabain in experiments with HCY, suggesting that CaMKII is not involved in this process. From these observations, we may conclude that in the condition of hyperhomocysteinemia, both PKA and PKC are required for anti-apoptotic signaling pathways triggered by ouabain.

\section{Discussion}

It is widely accepted that $\operatorname{Glu}[16,18,19,45]$ and $\operatorname{HCY}[7,8]$ induced neurodegeneration is caused by the permanent plasma membrane depolarization and cytosolic $\mathrm{Ca}^{2+}$ overload of neurons, which is the condition known as excitotoxic stress [for review 45]. Under the excitotoxic stress, the maintenance of ionic gradients on the plasma membrane by NKA consumes ATP and burdens mitochondria, which, as a consequence, is followed by the loss of mitochondrial inner membrane voltage. This particular situation could be illustrated by the disruption of the mitochondrial respiratory chain with CCCP and subsequent total loss of inner membrane voltage. Furthermore, water entry via ionotropic receptor channels to balance an accumulation of ions inside of neurons and a low $\mathrm{Na}^{+}$membrane gradient can result in neuroinflammation with fast necrosis of neurons. In addition, a long-term elevation of cytosolic $\mathrm{Ca}^{2+}$ and mitochondrial dysfunction can trigger intracellular signaling cascades of apoptosis. Overall our data concerning the effects of Glu and HCY on neurons are consistent with this concept of excitotoxicity. We, therefore, further consider the mechanisms of neuroprotection by a subnanomolar concentration of ouabain.

\section{Necrosis at short-term excitotoxic stress}

The short-term (4 h) action of both Glu and HCY resulted in a considerable increase of necrotic neurons. This effect was abolished by the combined application of agonists with $0.1 \mathrm{nM}$ or $1 \mathrm{nM}$ ouabain. Presumably, in a portion of neurons, the plasma membrane depolarization and $\mathrm{Ca}^{2+}$ overload evoked by Glu or HCY engage energy-consuming ionic homeostasis, which leads to a rapid depletion of ATP resources required for the maintenance of ion balance and coupled water transport. In experiments, these processes could be monitored by the loss of mitochondrial inner membrane potential. The above explanation is consistent with the earlier observation that NMDAR induced osmotic imbalance causes cell swelling $[46,47]$ and rapid necrosis of neurons [46]. 
In sort-term experiments, $\mathrm{HCY}$, as an excitotoxic agent, was less potent than Glu. This conclusion is supported by the observations that (1) the $\mathrm{Ca}^{2+}$ overload of neurons induced by HCY was less pronounced than as for Glu and (2) HCY caused a lesser drop of mitochondrial inner membrane voltage, which was found to be about $0.2\left(\Delta \varphi_{\text {mit }}\right)$ of the total drop $\left(\varphi_{\text {mit }}\right)$ caused by CCCP, than the $\Delta \varphi_{\text {mit }}$ value of about 0.7 found for Glu. As known, these agonists differ with respect to the activation of Glu receptors. While Glu activates all Glu receptors and does not cause desensitization of NMDARs, HCY activates only NMDARs and desensitizes those containing GluN2B subunits [12]. The latter ones are widely expressed in extrasynaptic regions of the plasma membrane, and it is thought to provide a major contribution to neurodegeneration [19]. Since rat cortical neurons express GluN2A and GluN2B [for review 48], the HCY effects are likely determined preferentially by the activation of GluN2A-containing NMDARs $[12,16,20]$. In contrast, Glu also activates GluN2B-containing NMDARs producing more $\mathrm{Ca}^{2+}$ to be accumulated in the cytoplasm and pronounced drop of the mitochondrial inner membrane potential, which is usually associated with mitochondrial swelling and neuronal cell death [49].

Subnanomolar concentrations of ouabain applied with either Glu or HCY considerably reduced the intracellular $\mathrm{Ca}^{2+}$ accumulation and related drop of the mitochondrial inner membrane potential, which rescued neurons from ATP deficit and reduced necrosis of neurons (Fig. 7a). This emergency rescue of neurons is most likely determined by an acceleration of $\mathrm{Ca}^{2+}$ export from neurons by NCXs, which, as demonstrated previously, are functionally regulated by ouabain through interaction with NKAs [22]. Besides, ouabain considerably decreased $\mathrm{Ca}^{2+}$ transients generated in some neurons on agonist application, which coincides well with the previous data that ouabain lowers the frequency of spontaneous excitatory postsynaptic currents in cortical neurons [22]. In addition amplitudes of $\mathrm{Ca}^{2+}$ transients are controlled by the local interplay of ouabain sensitive a3NKA, NCX and pre-membrane endoplasmatic reticulum $[22,50]$. It seems unlikely that this mechanism of intracellular $\mathrm{Ca}^{2+}$ regulation is specific for NMDARs because, as shown earlier, an increase of intracellular $\left[\mathrm{Ca}^{2+}\right]$ elicited by kainite activation of AMPA/kainite receptors is also well prevented by $1 \mathrm{nM}$ ouabain [23].

\section{Apoptosis at short-term excitotoxic stress}

Short excitotoxic insults induced by Glu in our experiments caused the increase of p53, AlF, Bax, which are pro-apoptotic proteins, expression, and Cas-3 activation in neurons, which was accompanied by loss of Bcl-2. Presumably, Glu elicited elevation of intracellular $\left[\mathrm{Ca}^{2+}\right]$, and loss of mitochondrial inner membrane voltage lead to the opening of $\mathrm{Bcl}-2$ controlled permeability transition pore of mitochondria and releases of AIF, Cytochrome-C and other pro-apoptotic factors which initiate apoptosis [51]. In consistence with previous studies, we may suggest that $4 \mathrm{~h}$ Glu insults cause an elevation of p53 expression resulting in a subsequent Bax activation [52], which may enhance NMDA elicited $\mathrm{Ca}^{2+}$ transients and contribute to deregulation of $\varphi_{\text {mit }}$ [53]. Previously it has been demonstrated that ouabain at nanomolar concentrations causes a reduction of p53 expression by activation of Src/mitogenactivated protein kinase (MAPK) signaling pathways upon its binding to the NKA [54]. Therefore, ouabain 
induced signaling may prevent the up-regulation and mitochondrial recruitment of $B a x[55,56]$, which opposes $\mathrm{Ca}^{2+}$-induced mitochondrial dysfunction and apoptosis (Fig. 7b).

Cas-3 is protease-activated by both extrinsic and intrinsic (mitochondrial) apoptotic pathways [51] and acts at late irreversible stages of apoptosis. Prevention of Cas-3 activation by ouabain during $4 \mathrm{~h}$ excitotoxic insults most likely exhibits that this cardiotonic steroid may induce inactivation of most upstream pro-apoptotic signaling cascades.

Regardless of the observations that Glu effects on $\mathrm{Ca}^{2+}$ accumulation and the loss of mitochondrial inner membrane voltage are more pronounced than the effects of HCY, both Glu and HCY caused a similar increase of neuronal apoptosis after $4 \mathrm{~h}$ treatment. Ouabain also produced similar protection against apoptosis and necrosis in the case of $4 \mathrm{~h}$ incubation with both $\mathrm{HCY}$ and Glu. By the use of specific inhibitors, we show that PKC, PKA or CaMKII are not involved in ouabain neuroprotection at $4 \mathrm{~h}$ excitotoxic stress. Most likely, anti-apoptotic mechanisms such as CREB phosphorylation by PKA or PKC [57] do not contribute to the ouabain effects in the short excitotoxic insults.

\section{Apoptosis at long-term excitotoxic stress}

The long-term $24 \mathrm{~h}$ treatment of neurons with Glu or HCY significantly increased the fraction of apoptotic but not necrotic neurons. Ouabain at $1 \mathrm{nM}$ effectively prevented neuronal apoptosis against $24 \mathrm{~h}$ treatments by both Glu and HCY. Inhibition of CaMKII had no effect on ouabain mediated anti-apoptotic action. This differs ouabain induced neuroprotection from CGRP and forskolin elicited one [40,58], which required CaMKII activation and cAMP-dependent PKA activation.

The inhibition of PKA or PKC blocked ouabain induced neuroprotection against HCY, but not against Glu neurotoxicity. This observation can be related to the NMDAR subtype selectivity of HCY because GluN2A, but not GluN2B NMDAR subunits, mostly contribute to HCY toxicity in cortical neurons $[12,14-16]$ and reflect extensive recruitment of different glutamate ionotropic and metabotropic receptors and transporters in glutamate neurotoxicity.

This indirectly supports the idea that HCY activates unique pro-apoptotic mechanisms that differ from those induced by Glu. For example during long-term action HCY, but not Glu induces GluN2A dependent sustained activation of ERK2 MAPK $[8,59]$, internalization of the $\mathrm{Ca}^{2+}$-impermeable GluA2-subunit of AMPA receptors and increase of intracellular $\left[\mathrm{Ca}^{2+}\right][60]$, which both cause permanent activation of p38 MAPK [14], downstream phosphorylation of Caspase-9 and apoptosis [for review 61]. Conversely, GluN2B containing extrasynaptic NMDARs over-activated by Glu induce only transient [59] ERK MAPK activation [17-19], while HCY causes sustained p38 MAPK activity [14]. As a result, p38 MAPK inhibition can protect neurons from short-term, but not long-term activation of NMDARs [62]. In addition in the case of HCY, the toxicity caused by both $4 \mathrm{~h}$ [14] and $24 \mathrm{~h}$ [63] treatments can be prevented by p38 MAPK block. Taken together, these observations favor the assumption that NKA signaling could modulate p38 MAPK via some PKA or PKC dependent pathways. 


\section{The role of PKC and PKA in ouabain effects against hyperhomocysteinemia}

Previously we have demonstrated that neuronal apoptosis induced by $24 \mathrm{~h}$ treatment with HCY could be prevented by CGRP or forskolin, which both activated anti-apoptotic cAMP-dependent pathways. This type of neuroprotection depended mostly on PKA and CaMKII activity [40]. Ouabain induced neuroprotection against $24 \mathrm{~h} \mathrm{HCY}$ treatment of cortical neurons depended on PKA and PKC, but not CaMKII, which activity is mostly linked to the postsynaptic area [for review 64]. Therefore the long-term neuroprotection caused by ouabain must involve the apoptotic mechanisms, which are not yet activated at $4 \mathrm{~h}$, but already contribute in neurotoxicity at $24 \mathrm{~h}$ excitotoxic stress. The ouabain effects against longterm action of $\mathrm{HCY}$ can involve PKA and PKC dependent effects on some pro-apoptotic cascade upregulated by HCY, but not by Glu. Probably, HCY-specific pro-apoptotic cascade $[8,59]$ includes Caspase9 , and p38 MAPK, which both are susceptible to inactivation by phosphorylation with PKC $[65,66]$ (Fig. 7c), while Caspase-9 can be inactivated by PKA or PKC to interrupt apoptosis [67] (Fig. 7c, d). Subnanomolar ouabain activates PKC [68], which provides a possible explanation for observed ouabain induced neuroprotection in hyperhomocysteinemia.

\section{Conclusions}

Effects of short-term treatments of cortical neurons with Glu and HCY differ in many aspects of neurotoxic action, including the intensity of cytosolic $\mathrm{Ca}^{2+}$ accumulation and the loss of mitochondrial inner membrane voltages. However, these compounds turned out to be similar with respect to there efficacy to cause necrosis and apoptosis of neurons found in $4 \mathrm{~h}$ excitotoxic insults. Under these conditions the neuroprotection results from the NKA mediated acceleration of $\mathrm{Ca}^{2+}$ export from neurons that avoids the mitochondrial dysfunction and prevents the development of mitochondrial and caspasedependent pro-apoptotic cascades. At this particular stage of HCY neurotoxic insult, PKA, PKA, and CaMKII are not necessarily involved in the neuroprotection caused by ouabain or $4 \mathrm{~h}$ insult duration is not enough for these kineses to be activated. Most likely, the improvement of neuronal ionic balance produced by NKA/NCX mediated signaling is sufficient to prevent both the development of necrosis and apoptosis.

Ouabain effects during long-term $24 \mathrm{~h}$ treatment with Glu still do not involve kinase-dependent signaling, while PKC and PKA activity is required for ouabain effects to prevent apoptosis caused by HCY. Unlike Glu, HCY is able to induce the specific GluN2A subunit dependent sustained activation of ERK/p38/Cas9/Cas-3 pathway. This pro-apoptotic pathway is susceptible to the inhibitory phosphorylation by PKC and PKA but does not depend on CaMKII.

\section{Abbreviations}

$\left[\mathrm{Ca}^{2+}\right]$ - free intracellular calcium concentration; 
ATP - adenosine-3-phosphate;

CaMKII - $\mathrm{Ca}^{2+} /$ calmodulin-dependent protein kinase II;

Cas-3 and Cas-9 - Caspases 3 and 9;

CCCP - m-chlorophenyl hydrazone;

CGRP - calcitonin gene-related peptide;

CREB - cAMP response element-binding protein;

Glu - glutamate;

GluA2 - subunit of AMPA receptor;

GluN2A and GluN2B - subunits of N-methyl-D-aspartate receptors;

$\mathrm{HCY}$ - homocysteine;

MAPK - mitogen-activated protein kinase;

MTX - mitochondria;

NCX - sodium-calcium exchanger;

NKA - Na/K-ATPase;

Oua - ouabain;

PKA - proteinkinase A;

PKC - proteinkinase C;

PLC - phospholipase C;

Src - Src-kinase

$\varphi_{\text {mit }}$ - mitochondrial inner membrane potential.

\section{Declarations}

Ethics approval. All the experiments with rats were approved by the Bioethics Committee of Sechenov Institute of Evolutionary Physiology and Biochemistry of the Russian Academy of Sciences (IEPhB RAS).

Consent for publication. Not applicable. 
Availability of data and materials. All data generated or analysed during this study are included in this published article [and its supplementary information files].

Competing interests. The authors declare that they have no competing interests.

Funding. This work was supported by Russian Science Foundation Grant \#16-15-10192.

Authors' contributions. Study concept and design: SMA, PAA, DAS. Acquisition of data: MAI, ADK, PDT, TVK, PAA, JDS. Analysis and interpretation of the data: PAA, DAS, SMA. Statistical analysis: PAA, DAS. Drafting of the manuscript: PAA, DAS, SMA. All authors read and approved the final manuscript.

Acknowledgements. Imaging experiments were performed at the Resource Center of Sechenov Institute of Evolutionary Physiology and Biochemistry of the Russian Academy of Sciences.

\section{Table}

Table 1. The neuroprotective effect of ouabain against neurotoxicity induced by 4 h glutamate (Glu) or homocysteine $(\mathrm{HCY})$ treatment of rat cortical neurons.

\begin{tabular}{|c|c|c|c|c|c|}
\hline & Ouabain & & Live, \% & Apoptotitc, \% & Necrotic, \% \\
\hline \multirow[t]{3}{*}{ Control } & & $n=8$ & $85 \pm 1.2$ & $9 \pm 0.7$ & $5 \pm 0.9$ \\
\hline & $+0.1 \mathrm{nM}$ & $n=5$ & $85 \pm 2.3$ & $9 \pm 0.5$ & $6 \pm 1.9$ \\
\hline & $+1 \mathrm{nM}$ & $n=7$ & $84 \pm 2.6$ & $10 \pm 1.1$ & $2 \pm 1.7$ \\
\hline \multirow[t]{3}{*}{ Glu } & & $n=7$ & $48 \pm 4.9 * \star \star$ & $37 \pm 4.2$ *** & $14 \pm 2.3 * *$ \\
\hline & $+0.1 \mathrm{nM}$ & $n=8$ & $79 \pm 4.9$ & $12 \pm 4.1$ & $9 \pm 1.1$ \\
\hline & $+1 \mathrm{nM}$ & $n=9$ & $81 \pm 2.9$ & $10 \pm 2.2$ & $8 \pm 0.8$ \\
\hline \multirow[t]{3}{*}{$\mathrm{HCY}$} & & $n=6$ & $54 \pm 2.7 * \star \star$ & 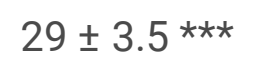 & $17 \pm 1 * \star \star$ \\
\hline & $+0.1 \mathrm{nM}$ & $n=7$ & $84 \pm 3.9$ & $7 \pm 1.9$ & $9 \pm 2.9$ \\
\hline & $+1 \mathrm{nM}$ & $n=8$ & $74 \pm 2.3$ & $13 \pm 2$ & $13 \pm 1.1$ \\
\hline
\end{tabular}

$\star \star, * \star \star$ - data are significantly different from control by one-way ANOVA with Tukey's post-hoc test.

\section{References}

1. Refsum H, Ueland PM, Nygard O, Vollset SE. Homocysteine and cardiovascular disease. Annu Rev Med. 1998;49:31-62. 
2. Sacco RL, Roberts JK, Jacobs BS. Homocysteine as a risk factor for ischemic stroke: an epidemiological story in evolution. Neuroepidemiology. 1998;17:167-73.

3. Huang G, Dragan M, Freeman D, Wilson JX. Activation of catechol-O-methyltransferase in astrocytes stimulates homocysteine synthesis and export to neurons. 2005;51: 47-55.

4. Hu XW, Qin SM, Li D, Hu LF, Liu CF. Elevated homocysteine levels in levodopa-treated idiopathic Parkinson's disease: a meta-analysis. Acta Neurol. Scand. 2013;128:73e82.

5. Miller JW. Homocysteine, Alzheimer's disease and cognitive function, Nutrition. 2000;16:675-77

6. Surtees R, Leung DYM, Bowron A, Leonard J. Cerebrospinal fluid and plasma total homocysteine and related metabolites in children with cystathionine b-synthase deficiency: the effect of treatment, Pediatr Res. 1997;42:577-82.

7. Lipton SA, Kim WK, Choi YB, Kumar S, D’Emilia DM, Rayudu P V, et al. Neurotoxicity associated with dual actions of homocysteine at the N-methyl-D-aspartate receptor. Proc Natl Acad Sci U S A. 1997;94:5923-8.

8. Poddar R, Paul S. Novel crosstalk between ERK MAPK and p38 MAPK leads to homocysteine-NMDA receptor-mediated neuronal cell death. J. Neurochem. 2013;124:558-70.

9. Tan B, Venketasubramanian N, Vrooman H, Cheng C-Y, Wong TY, Ikram MK, et al. Homocysteine and cerebral atrophy: the epidemiology of dementia in Singapore study. J Alzheimers Dis. 2018;62:87785.

10. Abushik PA, Niittykoski M, Giniatullina R, Shakirzyanova A, Bart G, Fayuk D, Sibarov DA, Antonov SM, Giniatullin R. The role of NMDA and mGluR5 receptors in calcium mobilization and neurotoxicity of homocysteine in trigeminal and cortical neurons and glial cells. J Neurochem. 2014;129:264-74.

11. Bolton AD, Phillips MA, Constantine-Paton M. Homocysteine reduces NMDAR desensitization and differentially modulates peak amplitude of NMDAR currents, depending on GluN2 subunit composition. J Neurophysiol. 2013; 110:1567-82.

12. Sibarov DA, Abushik PA, Giniatullin R, Antonov SM. GluN2A subunit-containing NMDA receptors are the preferential neuronal targets of homocysteine. Front Cell Neurosci. 2016;10:246.

13. Sibarov DA, Giniatullin R, Antonov SM. High sensitivity of cerebellar neurons to homocysteine is determined by expression of GluN2C and GluN2D subunits of NMDA receptors. Biochem Biophys Res Commun. 2018;506:648-52.

14. Rajagopal S, Fitzgerald AA, Deep SN, Paul S, Poddar R. Role of GluN2A NMDA receptor in homocysteine-induced prostaglandin E2 release from neurons. J Neurochem. 2019;150:44-55

15. Jindal A, Rajagopal, S.; Winter, L.; Miller, J.W.; Jacobsen, D.W.; Brigman, J.; Allan, A.M.; Paul, S.; Poddar, R. Hyperhomocysteinemia leads to exacerbation of ischemic brain damage: Role of GluN2A NMDA receptors. Neurobiol Dis. 2019;127:287-302.

16. Deep SN, Mitra S, Rajagopal S, Paul S, Poddar R. GluN2A-NMDA receptor-mediated sustained Ca ${ }^{2+}$ influx leads to homocysteine-induced neuronal cell death. J Biol Chem. 2019;294:11154-65. 
17. Kim MJ, Dunah AW, Wang YT, Sheng M. Differential roles of NR2A- and NR2B-containing NMDA receptors in Ras-ERK signaling and AMPA receptor trafficking. Neuron. 2005;46:745-60.

18. Liu Y, Wong TP, Aarts M, Rooyakkers A, Liu L, Lai TW, Wu DC, Lu J, Tymianski M, Craig AM, Wang YT NMDA receptor subunits have differential roles in mediating excitotoxic neuronal death both in vitro and in vivo. J Neurosci. 2007;27:2846-57.

19. Hardingham GE, Fukunaga $Y$, Bading $H$. Extrasynaptic NMDARs oppose synaptic NMDARs by triggering CREB shut-off and cell death pathways. Nat Neurosci. 2002;5:405-14.

20. Montecinos-Oliva C, Arrázola MS, Jara C, Tapia-Rojas C, Inestrosa NC. Hormetic-like effects of Lhomocysteine on synaptic structure, function, and $A \beta$ aggregation. Pharmaceuticals. 2020; doi: 10.3390/ph13020024.

21. Yakovlev AV, Kurmashova E, Zakharov A, Sitdikova GF. Network-driven activity and neuronal excitability in hippocampus of neonatal rats with prenatal hyperhomocysteinemia. Bionanoscience. 2018;8:304-9.

22. Sibarov DA, Bolshakov AE, Abushik PA, Krivoi II, Antonov SM. $\mathrm{Na}^{+}, \mathrm{K}^{+}-A T P a s e$ functionally interacts with the plasma membrane $\mathrm{Na}^{+}, \mathrm{Ca}^{2+}$ exchanger to prevent $\mathrm{Ca}^{2+}$ overload and neuronal apoptosis in excitotoxic stress. J Pharmacol Exp Ther. 2012; 343:596-607.

23. Abushik PA, Sibarov DA, Eaton MJ, Skatchkov SN, Antonov SM. Kainate-induced calcium overload of cortical neurons in vitro: Dependence on expression of AMPAR GluA2-subunit and down-regulation by subnanomolar ouabain. Cell Calcium. 2013;54: 95-104.

24. Ivanova MA, Sitnikova LS, Stepanenko YD, Karelina TV, Sibarov DA, Abushik PA, Antonov SM. Forskolin as a neuroprotector and modulator of glutamate-evoked $\mathrm{Ca}^{2+}$ entry into cerebellar neurons. Biochem Suppl Ser A Membr Cell Biol. 2018;12: 390-3.

25. Pierre SV, Xie Z. The Na,K-ATPase receptor complex: its organization and membership. Cell Biochem Biophys. 2006;46:303-16.

26. Aperia A. New roles for an old enzyme: Na,K-ATPase emerges as an interesting drug target. $J$ Intern Med. 2007;261:44-52.

27. Lingrel JB. The physiological significance of the cardiotonic steroid/ ouabain-binding site of the Na,K-ATPase. Annu Rev Physiol. 2010;72:395-412.

28. Reinhard L, Tidow H, Clausen MJ, Nissen P. Na,K-ATPase as a docking station: protein-protein complexes of the Na,K-ATPase. Cell Mol Life Sci. 2013;70:205-22.

29. Aperia A, Akkuratov EE, Fontana JM, Brismar H. $\mathrm{Na}^{+}-\mathrm{K}^{+}$-ATPase, a new class of plasma membrane receptors. Am J Physiol Cell Physiol. 2016;310:C491-C495.

30. Gao J, Wymore RS, Wang Y, Gaudette GR, Krukenkamp IB, Cohen IS, Mathias RT. Isoform-specific stimulation of cardiac $\mathrm{Na} / \mathrm{K}$ pumps by nanomolar concentrations of glycosides. J Gen Physiol. 2002;119:297-312.

31. Bolshakov AE, Sibarov DA, Abushik PA, Krivoi II, Antonov SM. Dose-dependence of antiapoptotic and toxic action of ouabain in neurons of primary cultures of rat cortex. Biochem Suppl Ser A Membr Cell 
Biol. 2012;6:294-9.

32. Haas M, Askari A, Xie Z. Involvement of Src and epidermal growth factor receptor in the signaltransducing function of $\mathrm{Na}^{+} / \mathrm{K}^{+}$-ATPase. J Biol Chem. 2000;275:27832-7.

33. Zhang S, Malmersjö S, Li J, Ando H, Aizman O, Uhlén P, Mikoshiba K, Aperia A. Distinct role of the Nterminal tail of the $\mathrm{Na}, \mathrm{K}-\mathrm{ATP}$ ase catalytic subunit as a signal transducer. J Biol Chem. 2006;281:21954-62.

34. Feldmann T, Shahar M, Baba A, Matsuda T, Lichtstein D, Rosen $\mathrm{H}$. The $\mathrm{Na}^{+} / \mathrm{Ca}^{2+}$-exchanger: an essential component in the mechanism governing cardiac steroid-induced slow $\mathrm{Ca}^{2+}$ Cell Calcium. 2011;50:424-32.

35. Liu L, Zhao X, Pierre SV, Askari A. Association of PI3K-Akt signaling pathway with digitalis-induced hypertrophy of cardiac myocytes. Am J Physiol Cell Physiol. 2007;293:C1489-C1497.

36. Sibarov DA, Abushik PA, Poguzhelskaya EE, Bolshakov KV, Antonov SM. Inhibition of plasma membrane $\mathrm{Na} / \mathrm{Ca}$-exchanger by KB-R7943 or lithium reveals its role in Ca-dependent N-methyl-Daspartate receptor inactivation. J Pharmacol Exp Ther. 2015;355:484-95.

37. Sibarov DA, Poguzhelskaya EE, Antonov SM. Downregulation of calcium-dependent NMDA receptor desensitization by sodium-calcium exchangers: a role of membrane cholesterol. BMC Neurosci. 2018;19:73.

38. Dvela-Levitt M, Ami HCB, Rosen H, Shohami E, Lichtstein D. Ouabain improves functional recovery following traumatic brain injury. J Neurotrauma. 2014;31:1942-47.

39. Greco R, Tassorelli C, Sandrini G, Di Bella P, Buscone S, Nappi G. Role of calcitonin gene-related peptide and substance $P$ in different models of pain. Cephalalgia. 2008;28:114-26.

40. Abushik PA, Bart G, Korhonen P, Leinonen H, Giniatullina R, Sibarov DA, Levonen AL, Malm T, Antonov SM, Giniatullin R. Pro-nociceptive migraine mediator CGRP provides neuroprotection of sensory, cortical and cerebellar neurons via multi-kinase signaling. Cephalalgia. 2017;37:1373-83.

41. Mironova EV, Evstratova AA, Antonov SM. A fluorescence vital assay for the recognition and quantification of excitotoxic cell death by necrosis and apoptosis using confocal microscopy on neurons in culture. J Neurosci Methods. 2007;163:1-8.

42. Han EB, Stevens CF. Development regulates a switch between post- and presynaptic strengthening in response to activity deprivation. Proc Natl Acad Sci U.S.A. 2009;106:10817-22.

43. Duchen MR. Mitochondria, calcium-dependent neuronal death and neurodegenerative disease. Pflügers Archiv. 2012;464:111-21.

44. Adams JM, Cory S. The Bcl-2 protein family: Arbiters of cell survival. Science. 1998;281:1322-6.

45. Khodorov B. Glutamate-induced deregulation of calcium homeostasis and mitochondrial dysfunction in mammalian central neurones. Prog Biophys Mol Biol. 2004;86: 279-351.

46. Sakaguchi T, Kuno M, Kawasaki K. Disparity of cell swelling and rapid neuronal death by excitotoxic insults in rat hippocampal slice cultures. Neurosci Lett. 1999;274:135-8. 
47. Isokawa M. N-methyl-D-aspartic acid-induced and Ca-dependent neuronal swelling and its retardation by brain-derived neurotrophic factor in the epileptic hippocampus. Neuroscience. 2005;131:801-12.

48. Paoletti P, Bellone C, Zhou Q. NMDA receptor subunit diversity: impact on receptor properties, synaptic plasticity and disease. Nat Rev Neurosci. 2013;14:383-400.

49. Choo AM, Geddes-Klein DM, Hockenberry A, Scarsella D, Mesfin MN, Singh P, Patel TP, Meaney DF. NR2A and NR2B subunits differentially mediate MAP kinase signaling and mitochondrial morphology following excitotoxic insult. Neurochem Int. 2012;60:506-16.

50. Blaustein MP, Juhaszova M, Golovina VA, Church PJ, Stanley EF. Na/Ca exchanger and PMCA localization in neurons and astrocytes: functional implications. Ann N Y Acad Sci. 2002:976:356-66.

51. Ghavami S, Hashemi M, Ande SR, Yeganeh B, Xiao W, Eshraghi M, Bus CJ, Kadkhoda K, Wiechec E, Halayko AJ, Los M. Apoptosis and cancer: mutations within caspase genes. J Med Genet. 2009;46:497-510.

52. Chipuk JE, Kuwana T, Bouchier-Hayes L, Droin NM, Newmeyer DD, Schuler M, Green DR. Direct activation of Bax by p53 mediates mitochondrial membrane permeabilization and apoptosis. Science. 2004;303:1010-4.

53. D'Orsi B, Kilbride SM, Chen G, Perez Alvarez S, Bonner HP, Pfeiffer S, Plesnila N, Engel T, Henshall DC, Düssmann H, Prehn JH. Bax regulates neuronal $\mathrm{Ca}^{2+}$ J Neurosci. 2015;35:1706-22.

54. Wang Z, Zheng M, Li Z, Li R, Jia L, Xiong X, Southall N, Wang S, Xia M, Austin CP, Zheng W, Xie Z, Sun Y. Cardiac glycosides inhibit p53 synthesis by a mechanism relieved by Src or MAPK inhibition. Cancer research. 2009;69, 6556-64.

55. Burlaka I, Liu XL, Rebetz J, Arvidsson I, Yang L, Brismar H, Karpman D, Aperia A. Ouabain protects against Shiga toxin-triggered apoptosis by reversing the imbalance between Bax and Bcl-xL. J Am Soc Nephrol. 2013;24:1413-23.

56. Lauf PK, Alqahtani T, Flues K, Meller J, Adragna NC. Interaction between Na-K-ATPase and Bcl-2 proteins BcIXL and Bak. Am J Physiol Cell Physiol. 2015;308:C51-C60.

57. Mao LM, Tang Q, Wang JQ. Protein kinase C-regulated cAMP response element-binding protein phosphorylation in cultured rat striatal neurons. Brain Res Bull. 2007;72:302-8.

58. Ivanova MA, Sitnikova LS, Karelina TV, Sibarov DA, Abushik PA, Antonov SM. The Neuroprotective effect of forskolin and its influence of mitochondrial dysfunction in neurons in primary rat cerebellum cultures. Neurosci Behav Physi. 2019;49: 1096-99.

59. Poddar R, Paul S. Homocysteine-NMDA receptor-mediated activation of extracellular signalregulated kinase leads to neuronal cell death. J Neurochem. 2009;110:1095-106.

60. Poddar R, Chen A, Winter L, Rajagopal S, Paul S. Role of AMPA receptors in homocysteine-NMDA receptor-induced crosstalk between ERK and p38 MAPK. J. Neurochem. 2017;142:560-573.

61. Allan LA, Clarke PR. Apoptosis and autophagy: Regulation of caspase-9 by phosphorylation. The FEBS Journal. 2009;276:6063-6073. 
62. Legos JJ, McLaughlin B, Skaper SD, Strijbos PJ, Parsons AA, Aizenman E, Herin GA, Barone FC, Erhardt JA. The selective p38 inhibitor SB-239063 protects primary neurons from mild to moderate excitotoxic injury. Eur J Pharmacol. 2002;447:37-42.

63. Wang X, Cui L, Joseph J, Jiang B, Pimental D, Handy DE, Liao R, Loscalzo J. Homocysteine induces cardiomyocyte dysfunction and apoptosis through p38 MAPK-mediated increase in oxidant stress. J Mol Cell Cardiol. 2012;52:753-60.

64. Woolfrey KM, Dell'Acqua ML. Coordination of Protein Phosphorylation and Dephosphorylation in Synaptic Plasticity. J Biol Chem. 2015; 290:28604-12.

65. Brady SC, Allan LA, Clarke PR. Regulation of caspase 9 through phosphorylation by protein kinase $C$ zeta in response to hyperosmotic stress. Mol Cell Biol. 2005; 25:10543-55.

66. Serrano BP, Hardy JA. Phosphorylation by protein kinase A disassembles the caspase-9 core. Cell Death Differ. 2018; 25:1025-39.

67. Maher $\mathrm{P}$. How protein kinase $\mathrm{C}$ activation protects nerve cells from oxidative stress-induced cell death. J Neurosci. 2001;21:2929-38.

68. Corrêa Gde R, Cunha KC, dos Santos AA, de Araujo EG. The trophic effect of ouabain on retinal ganglion cell is mediated by EGF receptor and PKC delta activation. Neurochem Res. 2010;35:134352 .

\section{Figures}


a

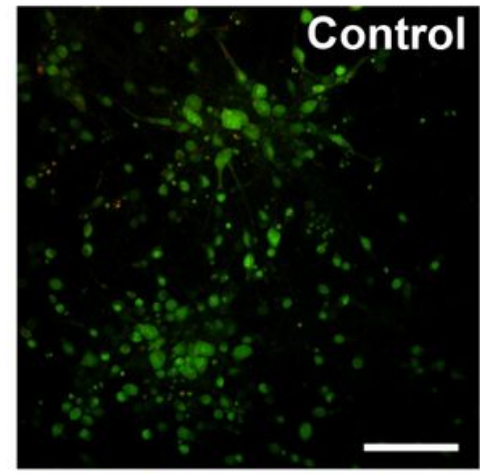

b

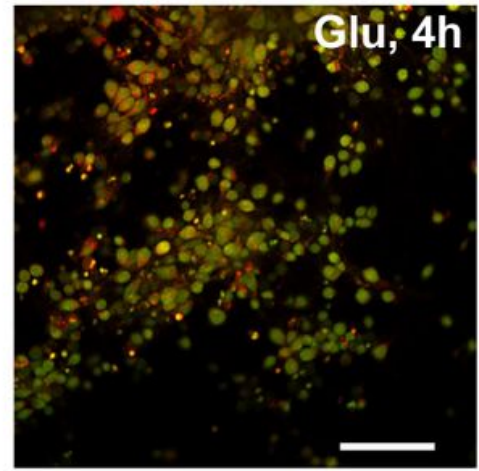

C

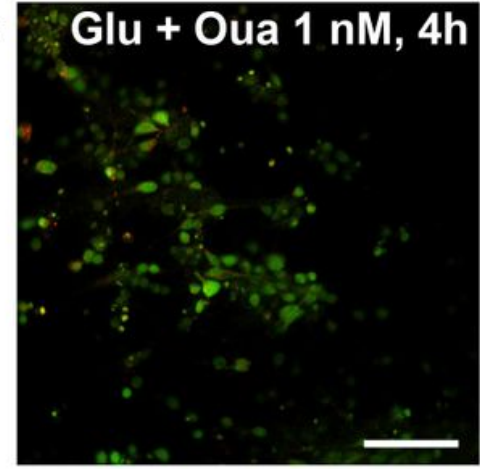

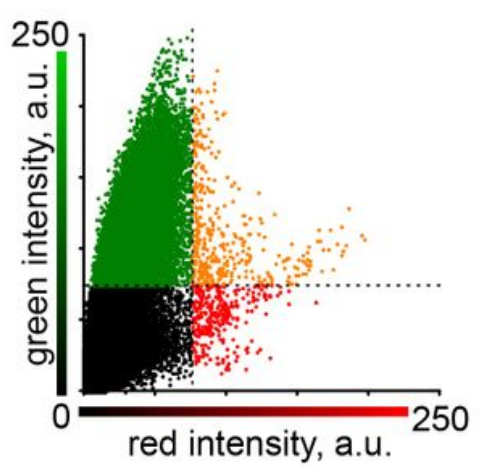
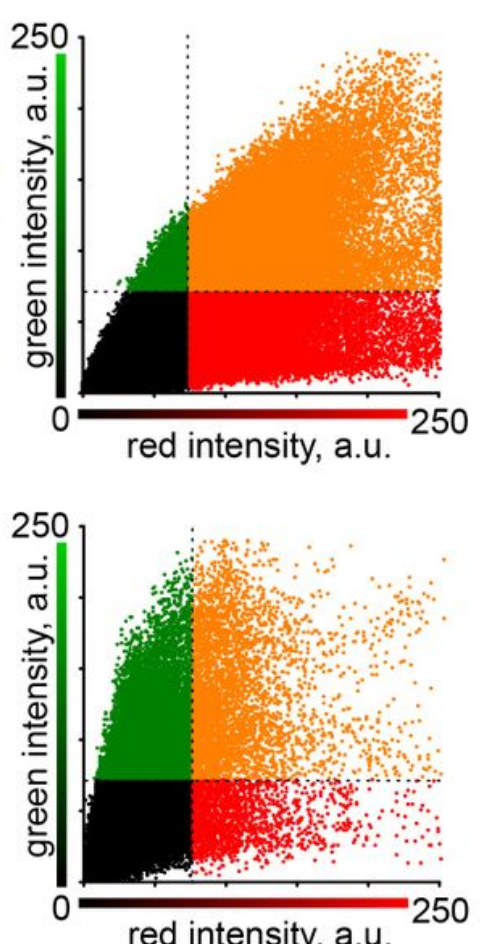

d
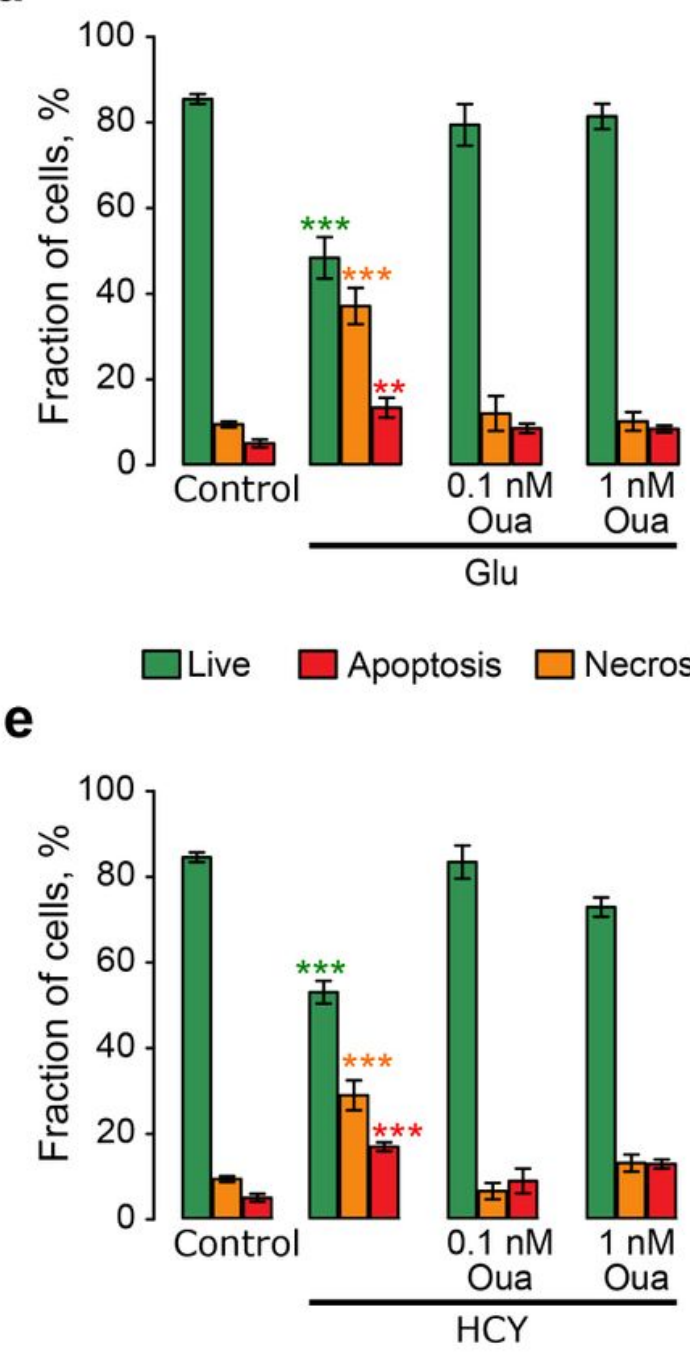

\section{Figure 1}

Neuroprotective effect of ouabain (Oua) against neurotoxicity induced by $4 \mathrm{~h}$ excitotoxic insults in rat cortical neurons. ( $\mathrm{a}, \mathrm{b}$ and $\mathrm{c}$ ) Confocal images represent an overlay of those recorded in green and red spectral regions of rat cortical neurons after $4 \mathrm{~h}$ treatment with the bathing solution (control, panel a), and $100 \mu \mathrm{M}$ glutamate $+30 \mu \mathrm{M}$ glycine (Glu, panel b) and Glu with $1 \mathrm{nM}$ ouabain (Oua, c) obtained with the FVA. Scale bar, $100 \mu \mathrm{m}$. The correlation plots shown on the right of corresponding images allow estimation of the cell viability (percentages of live, necrotic and apoptotic neurons). (d) Histogram quantitatively compares the data obtained in control $(n=8)$ and in the presence Glu $(n=7)$ along and with $0.1 \mathrm{nM}(\mathrm{n}=8)$ or $1 \mathrm{nM}(\mathrm{n}=9)$ ouabain (Oua). Experimental conditions are indicated below the plots. Green columns represent percentages of live, red - of necrotic and orange - of apoptotic neurons. Mean values \pm SEM are plotted. Experimental conditions are indicated below the plots. $* \star(p=0.002), * \star *(p=$ 0.0001 ) - data are significantly different from control by one-way ANOVA with Tukey's post-hoc test. (e) Histogram quantitatively compares the data obtained in control $(n=8)$ and in the presence of $100 \mu \mathrm{M}$ 
homocysteine $+30 \mu \mathrm{M}$ glycine $(\mathrm{HCY}, \mathrm{n}=6)$ and $0.1(\mathrm{n}=7) \mathrm{nM}$ or $1 \mathrm{nM}(\mathrm{n}=8)$ ouabain (Oua). Mean values \pm SEM are plotted. Experimental conditions are indicated below the plots. Green columns represent percentages of live, red - of necrotic and orange - of apoptotic neurons. $* \star \star(p=0.0002)$ - data are significantly different from control by one-way ANOVA with Tukey's post-hoc test, $n=7$.

$\square$ Ctrl $\square$ Glu $\square$ Glu + Oua $1 \mathrm{nM}$

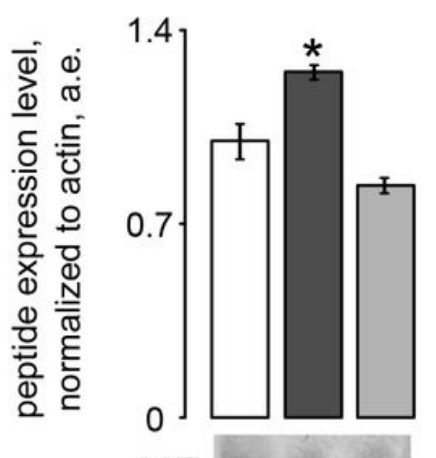

AIF
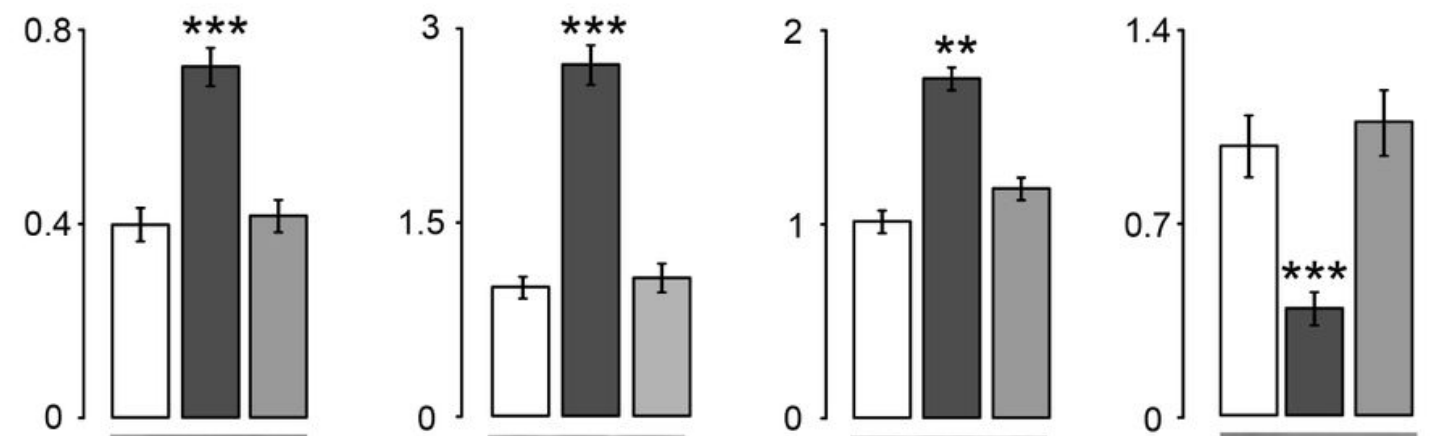

Cas-3

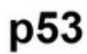

BAX

$\mathrm{Bcl}-2$

\begin{tabular}{r|ccccc}
$r$ & AlF & Cas-3 & p53 & BAX & Bcl-2 \\
\cline { 2 - 6 } Control & - & - & - & - & + \\
Glu & + & + & + & + & - \\
Glu + Oua & - & - & - & - & +
\end{tabular}

\section{Figure 2}

Ouabain prevents an expression of pro-apoptotic proteins induced by $4 \mathrm{~h}$ glutamate (Glu) treatment of cortical neurons. Glutamate inhibits expression of Bcl-2 and enhances expression of AIF, Cas-3, p53 and BAX. Co-application of Glu with $1 \mathrm{nM}$ ouabain (Oua) prevents pro-apoptotic protein expression so that the profile of protein expression remains similar to control values. Representative images of Western blots showing the proteins expression in Control, after $4 \mathrm{~h}$ treatment with $100 \mu \mathrm{M}$ glutamate $+30 \mu \mathrm{M}$ glycine and with $100 \mu \mathrm{M}$ glutamate $+30 \mu \mathrm{M}$ glycine $+1 \mathrm{nM}$ ouabain. For quantitative analysis the blots were scanned and the intensities of bands after normalizing to $\beta$-actin (not shown) were plotted as means \pm SEM ( $n=6$ for each bar). One-way ANOVA with Tukey's post-hoc test was utilized to reveal the significance of difference from control ( $*, p=0.03 ; * \star, p=0.005 ; * \star *, p=0.0002)$. 


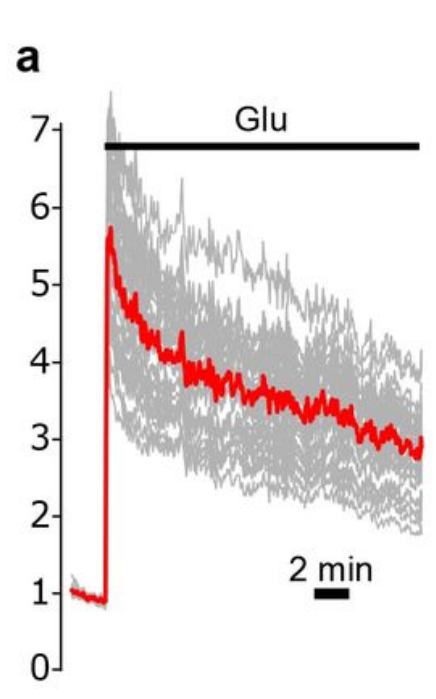

b
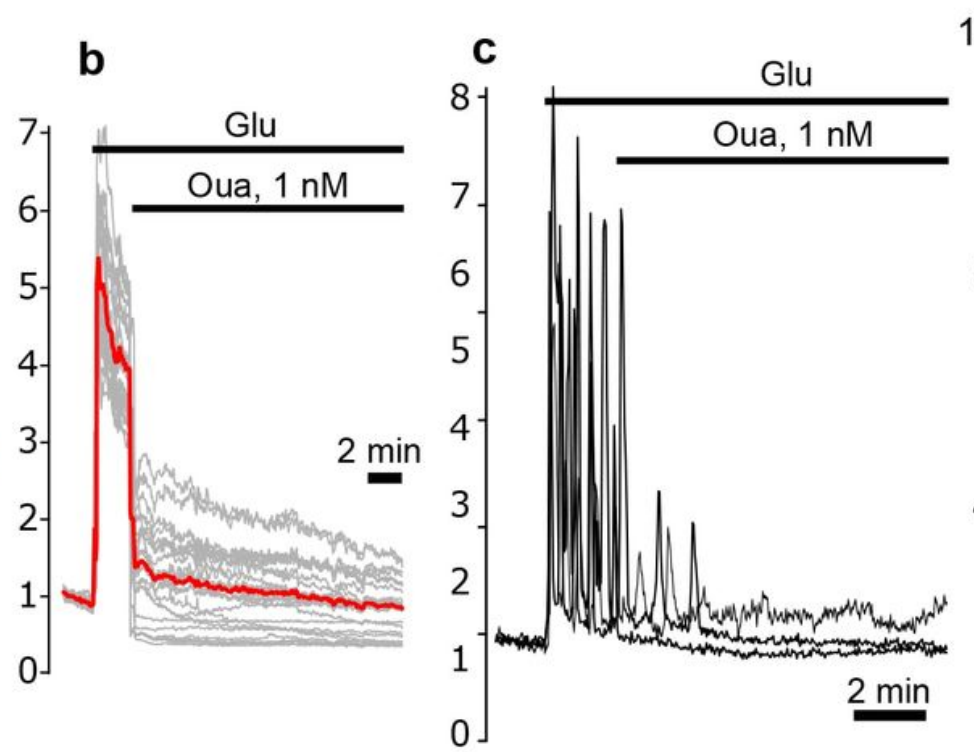

$1200-1 d$
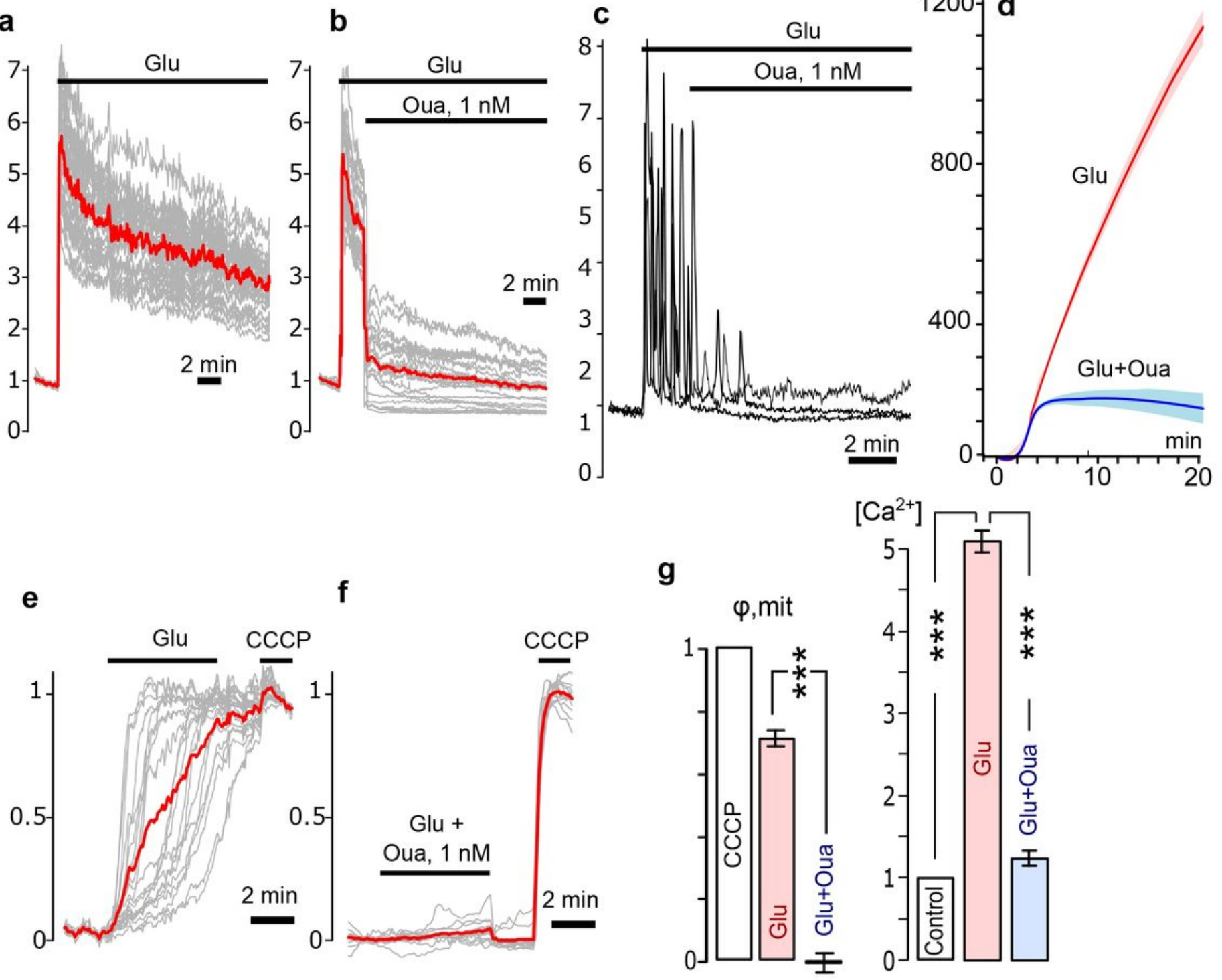

\section{Figure 3}

Ouabain prevents the intracellular $\mathrm{Ca} 2+$ overload and the loss of mitochondrial inner membrane potential of cortical neurons caused by glutamate. (a) Fluorescent Ca2+ responses of neurons loaded with Fluo-8 evoked by an application of $100 \mu \mathrm{M}$ glutamate $+30 \mu \mathrm{M}$ glycine (Glu) obtained from the same experiment and normalized to the fluorescence intensity recorded without Glu. Gray lines - responses of single neurons. Red line - an average response. (b) Similar to that shown in panel (a), except $1 \mathrm{nM}$ Oua was added on the top of responses. (c) Similar to that is shown in (b), except responses on Glu application revealed $\mathrm{Ca} 2+$ transients. (d) Average cumulative curves for Ca2+ overload evoked Glu (red line) and with an addition of Oua (blue line), that represent an integral of fluorescent $\mathrm{Ca} 2+$ responses shown in panels (a) and (b). Mean value \pm SEM for each point is plotted $(n=7)$. (e) Fluorescent responses of neurons loaded with Rhodamine-123 evoked by an application of $100 \mu \mathrm{M}$ glutamate $+30 \mu \mathrm{M}$ glycine (Glu) that reflect the loss of mitochondrial inner membrane voltage obtained from the same experiment and normalized to the fluorescence intensity recorded in the presence of $4 \mu \mathrm{M}$ CCCP. Gray lines - responses of single neurons. Red line - an average response. (f) Similar to that is shown in panel (e), except $1 \mathrm{nM}$ 
Oua was added to Glu. (g) Histograms compare average values for mitochondrial inner membrane potential ( $\varphi$ mit) obtained with Glu and combined application of Glu and Oua in relation to full loss of pmit in the presence of CCCP (on the left, $n=7$ ) and Ca2+ response amplitudes obtained under control and with Glu and combined application of Glu and Oua (on the right, $n=7$ ). ${ }^{* \star *}$ - data are significantly different ( $p=0.0006$, ANOVA with Tukey's post-hoc test).
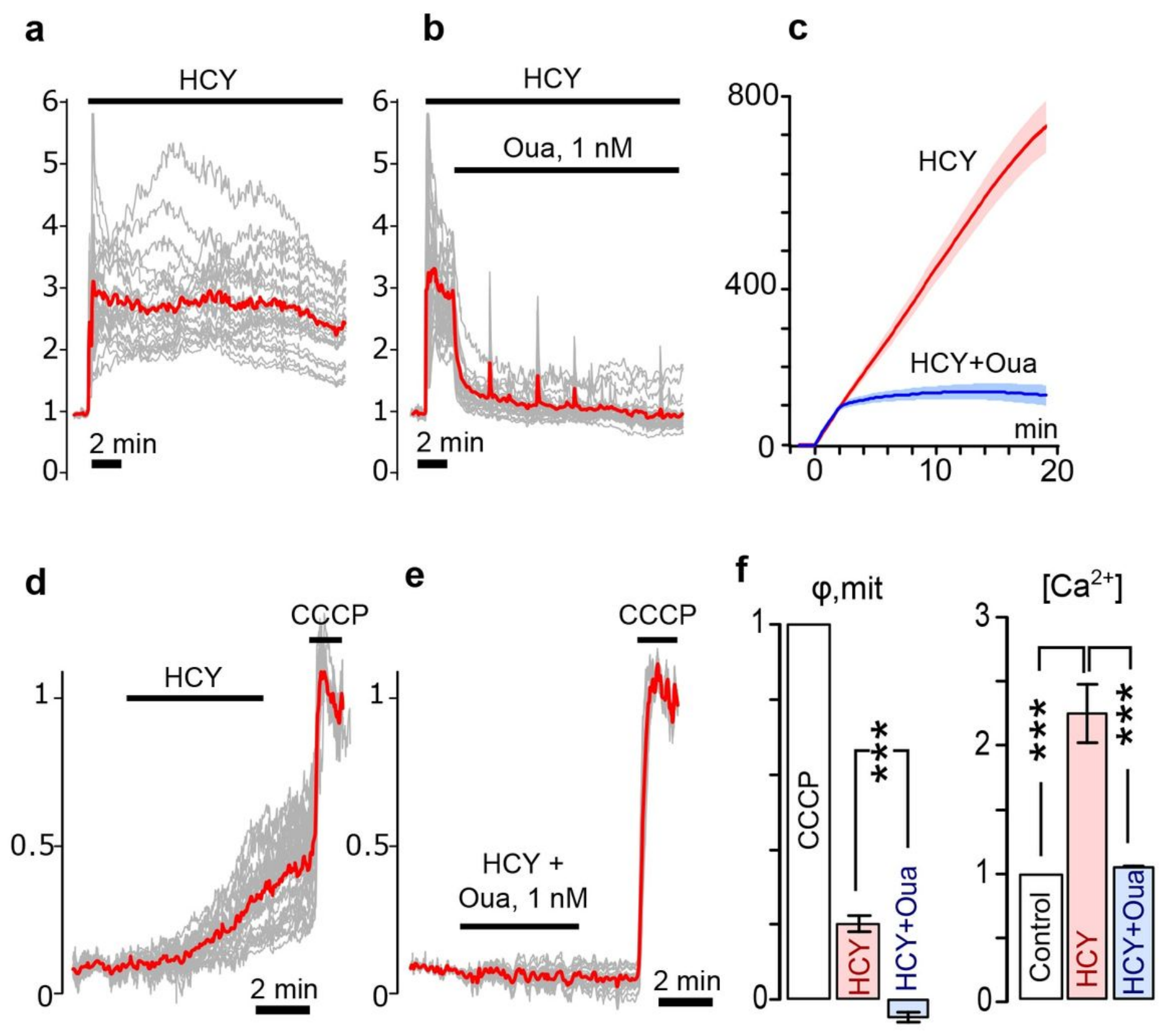

\section{Figure 4}

Ouabain prevents the intracellular $\mathrm{Ca} 2+$ overload and the loss of mitochondrial inner membrane potential of cortical neurons caused by homocystein. (a) Fluorescent $\mathrm{Ca} 2+$ responses of neurons loaded with Fluo8 evoked by an application of $100 \mu \mathrm{M}$ homocystein $+30 \mu \mathrm{M}$ glycine (HCY) obtained from the same experiment and normalized to the fluorescence intensity recorded without HCY. Gray lines - responses of single neurons. Red line - an average response. (b) Similar to that shown in panel (a), except $1 \mathrm{nM}$ Oua 
was added on the top of responses. (c) Average cumulative curves for $\mathrm{Ca} 2+$ overload evoked $\mathrm{HCY}$ (red line) and with an addition of Oua (blue line), that represent an integral of fluorescent $\mathrm{Ca} 2+$ responses shown in panels (a) and (b). Mean value \pm SEM for each point is plotted $(n=4)$. (d) Fluorescent responses of neurons loaded with Rhodamine-123 evoked by an application of $100 \mu \mathrm{M}$ homocystein +30 $\mu \mathrm{M}$ glycine $(\mathrm{HCY})$ that reflect the loss of mitochondrial inner membrane voltage obtained from the same experiment and normalized to the fluorescence intensity recorded in the presence of $4 \mu \mathrm{M} \mathrm{CCCP.} \mathrm{Gray}$ lines - responses of single neurons. Red line - an average response. (e) Similar to that is shown in panel (d), except $1 \mathrm{nM}$ Oua was added to HCY. (g) Histograms compare average values for mitochondrial inner membrane potential ( $\varphi$ mit) obtained with $\mathrm{HCY}$ and combined application of $\mathrm{HCY}$ and Oua in relation to full loss of $\varphi$ mit in the presence of CCCP (on the left, $n=5$ ) and Ca2+ response amplitudes ([Ca2+]) obtained under control and with Glu and combined application of HCY and Oua (on the right, $\mathrm{n}=5$ ). *** data are significantly different ( $p=0.0004$, ANOVA with Tukey's post-hoc test).

a

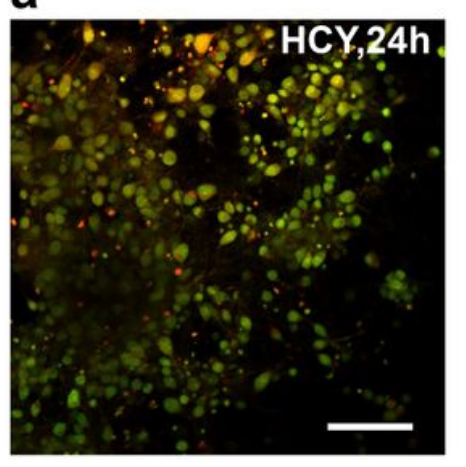

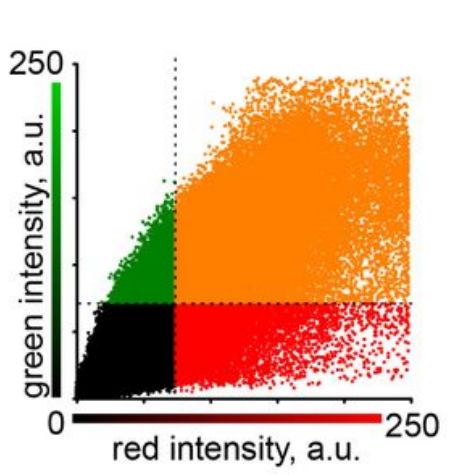
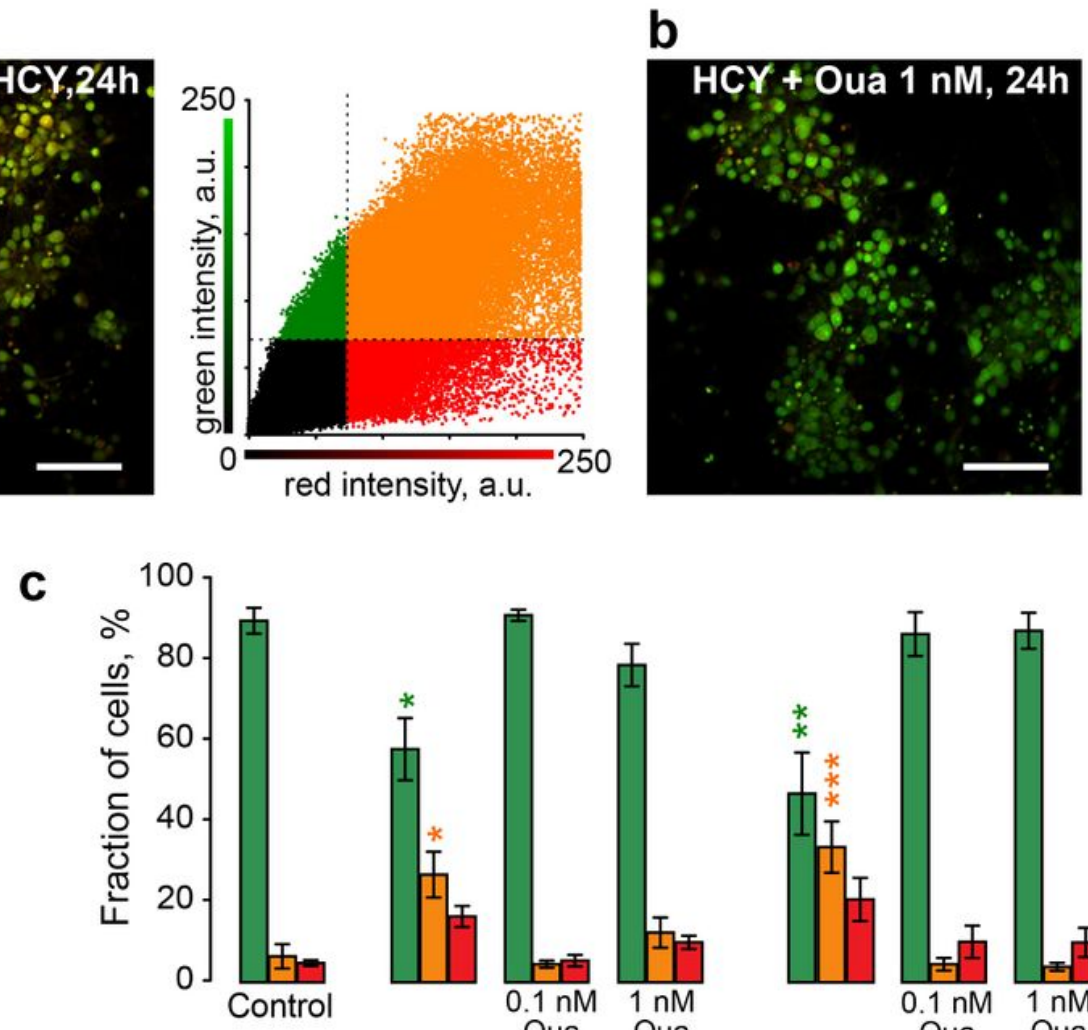

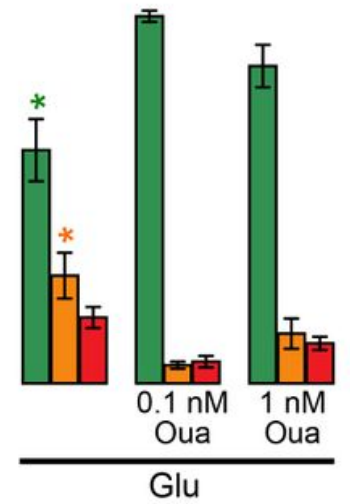

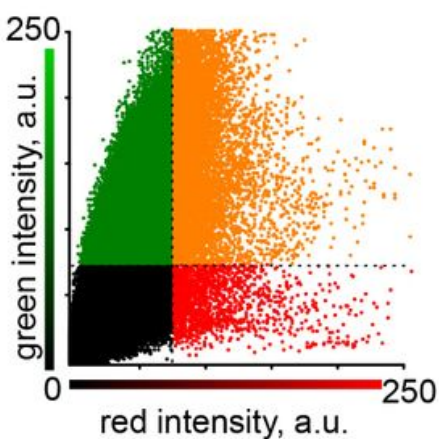

\section{Figure 5}

Neuroprotective effect of ouabain (Oua) against neurotoxicity induced by $24 \mathrm{~h}$ excitotoxic insults in rat cortical neurons. ( $a$ and $b$ ) Confocal images represent an overlay of those recorded in green and red spectral regions of rat cortical neurons after $24 \mathrm{~h}$ treatment with $100 \mu \mathrm{M}$ homocystein $+30 \mu \mathrm{M}$ glycine ( $\mathrm{HCY}$, panel a), and with an addition of $1 \mathrm{nM}$ ouabain (Oua, panel b) obtained with the FVA. Scale bar, 100 $\mu \mathrm{m}$. The correlation plots shown on the right of corresponding images allow estimation of the cell viability (percentages of live, necrotic and apoptotic neurons). (c) The histograms quantitatively compare 
the data obtained under control $(n=8)$ and after 24 hours exposure to $100 \mu \mathrm{M}$ glutamate $(\mathrm{Glu}, \mathrm{n}=8)$ or homocystein $(\mathrm{HCY}, \mathrm{n}=8)+30 \mu \mathrm{M}$ glycine and in combination with $0.1 \mathrm{nM}(\mathrm{n}=8)$ or $1 \mathrm{nM}(\mathrm{n}=8)$ ouabain (Oua). Mean values \pm SEM are plotted. Experimental conditions are indicated below the plot. Green columns represent percentages of live, red - of necrotic and orange - of apoptotic neurons. ${ }^{*}, * \star, * \star \star$ data are significantly different from control ( ${ }^{*}, p=0.03 ; * \star, p=0.002 ; * \star *, p=0.0008$; one-way ANOVA with Tukey's post-hoc test).

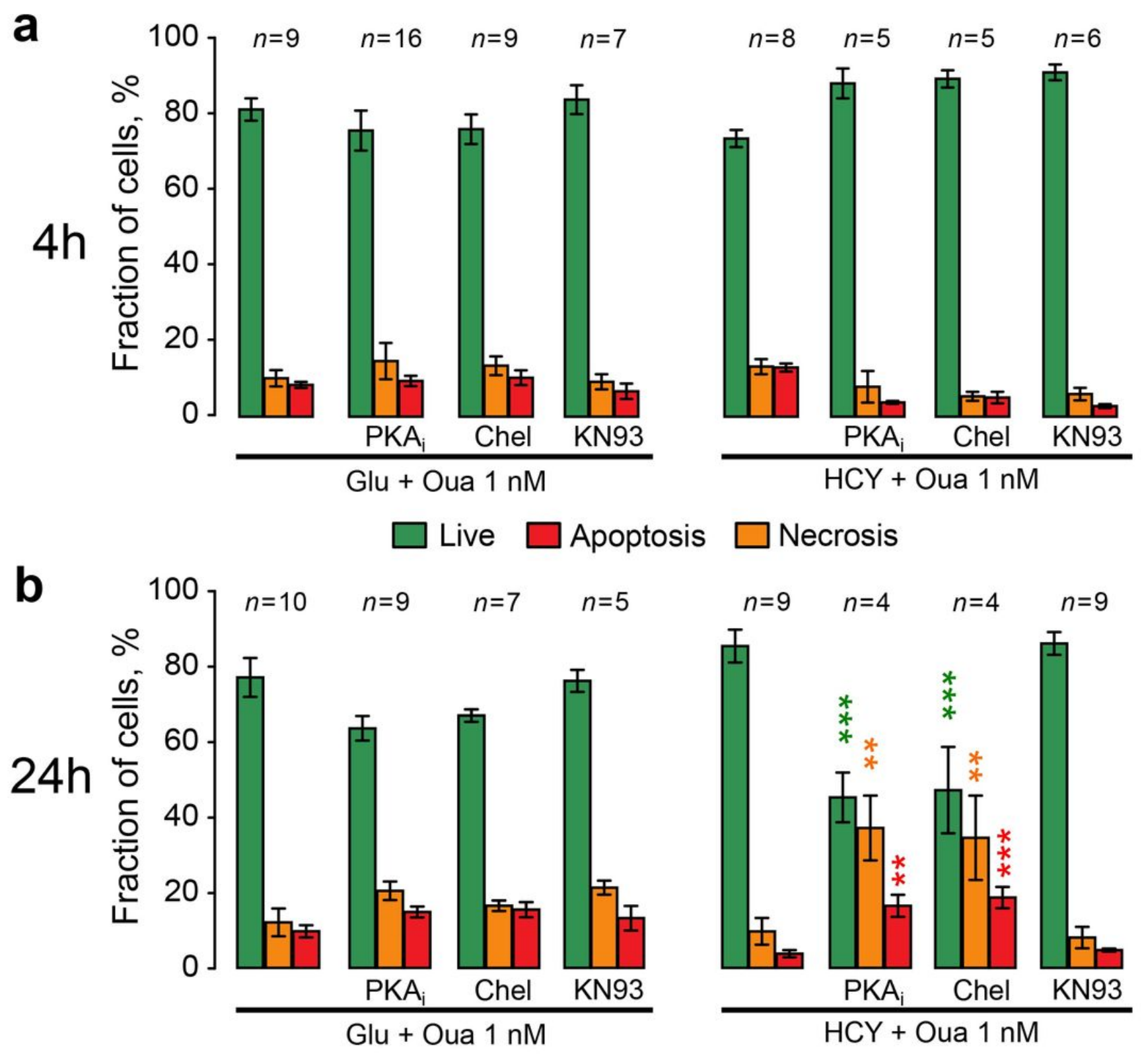

Figure 6

Effects of inhibitors of different protein kinases in ouabain induced neuroprotection in 4 and $24 \mathrm{~h}$ excitotoxic insults by glutamate and homocystein. (a) The histograms quantitatively compare the data obtained after $4 \mathrm{~h}$ exposure to $100 \mu \mathrm{M}$ glutamate (Glu) or homocystein (HCY) $+30 \mu \mathrm{M}$ glycine with $1 \mathrm{nM}$ ouabain (Oua) and in combination with 0.6 $\mu \mathrm{M}$ PKA inhibitor (PKAi), $1 \mu \mathrm{M}$ PKC inhibitor chelerythrine (Chel) or $3 \mu \mathrm{M}$ CaMKII inhibitor (KN93). Mean values \pm SEM are plotted. Experimental conditions are 
indicated below the plot. Green columns represent percentages of live, red - of necrotic and orange - of apoptotic neurons. (b) Similar to that shown in panel (a), except the duration of excitotoxic insult is $24 \mathrm{~h}$. $\star *, * \star *$ - data are significantly different from the values obtained in HCY with Oua ( $* *, p=0.009 ; * \star *, p=$ 0.0001; ANOVA with Tukey's post-hoc test). The number of experiments ( $n$ ) for each group is indicated above the columns.

$4 h$

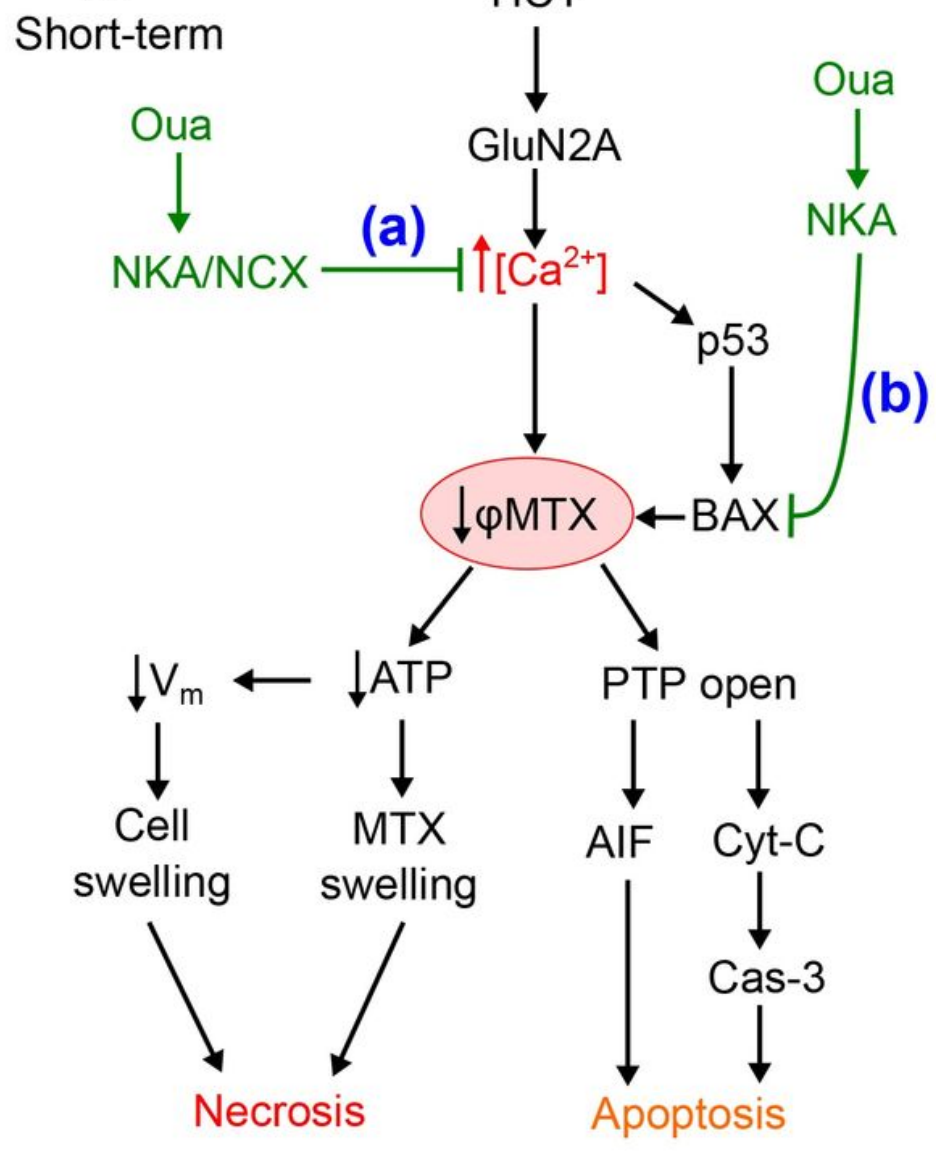

24h

Long-term
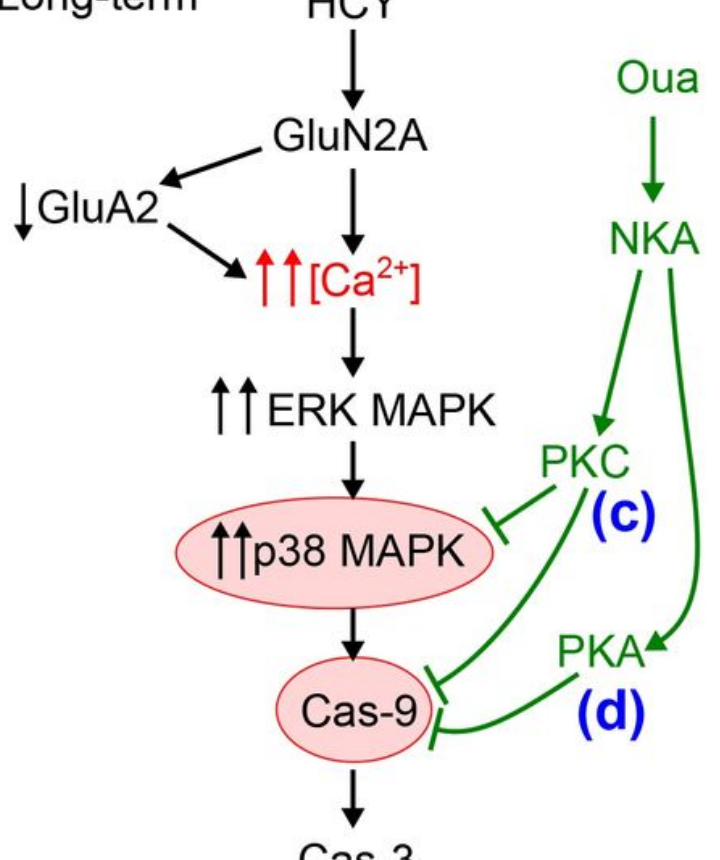

Cas-3

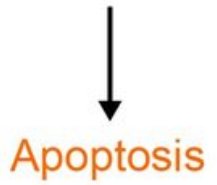

\section{Figure 7}

Schematics of data interpretation of antagonism between hyperhomocysteinemia induced neuronal death and ouabain triggered NKA signaling. The short-term ouabain effects are kinase-independent and include (a) acceleration of Ca2+ removal from the cell by NCX, (b) prevention of Bax translocation to mitochondria. Both (a) and (b) prevent severe ionic imbalance in neurons and augment downstream necrotic and apoptotic neuronal death. Long-term ouabain effects additionally involve PKC (c) and PKA (d) dependent inhibition of HCY-specific ERK/p38 MAPK apoptotic pathways. 